\title{
El masón Simón Bolívar entre el mito y la verdad histórica
}

\section{The Freemason Simón Bolívar between myth and historical truth}

\author{
José Antonio Ferrer Benimeli \\ Universidad de Zaragoza, España \\ bibliotecasalvadorzaragoza@gmail.com
}

Recepción: 25 de enero de 2020/Aceptación: 13 de marzo de 2020

doi: https://doi.org/10.15517/rehmlac.v12i1-2.40744

Palabras clave

Bolívar; masonería; historia; mito; Latinoamérica.

Keycords

Bolívar; Freemasonry; History; Myth; Latin America.

\section{Resumen}

La figura de Simón Bolívar con relación a la masonería, así como del resto de los próceres de las independencias hispanoamericanas sigue controvertida a pesar de las investigaciones que se han venido sucediendo estos últimos años para aclarar la cuestión. Se trata pues de actualizar los conocimientos históricos -no masónicos ni antimasónicos- sobre esa relación a través de los últimos estudios.

\section{Abstract}

The figure of Simón Bolívar in relation to Freemasonry, as well as the rest of the heroes of Spanish American independence, remains controversial despite recent research to clarify the issue. It is therefore a matter of updating historical knowledge -neither Masonic nor anti-Masonic- about this relationship through the latest studies. 


\section{Introducción}

Este trabajo es continuación y complemento del publicado en 1983 con motivo del bicentenario del nacimiento de Simón Bolívar (Caracas, 24 julio 1783) y de los presentados en 2014 en Cartagena de Indias en el IX Coloquio de Historia Social y de las Ciencias "La Masonería y la Independencia Americana” (Gran Logia Nacional de Colombia, 20-24 marzo); en 2017 en México en el Coloquio Internacional "Masonería y Sociedades Secretas" (UNAM, 12-13 junio) y en 2019 en Gijón (España) en el "Seminario permanente interdisciplinar de las masonerías" (Biblioteca Jovellanos, 22-25 febrero) ${ }^{1}$.

Los cuatro textos fueron escritos con la intención de superar “ideas, prejuicios y mitos’² Prejuicios y mitos que a fuerza de ser repetidos una y otra vez, al margen de la más elemental crítica histórica, han llegado a convertirse en dogmas históricos, poco menos que inamovibles, a pesar de su fragilidad histórico documental.

Este enfoque afecta, especialmente, a la presunta o real pertenencia a la masonería de los llamados próceres de la Independencia americana y en particular al caso del libertador Simón Bolívar ${ }^{3}$, el único de los que hay constancia documental fidedigna de que perteneció a una logia masónica, al menos en un período breve de su vida. Lo que no ocurre, por ejemplo, con Miranda, San Martín ${ }^{4}$, O’Higgins, Sucre y tantos otros convertidos en héroes y símbolos de la patria y de la masonería, aunque su filiación masónica no siempre resulte clara o tan suficientemente probada como la de Bolívar. Aquí, como afirma Alain Keghel, "la leyenda y el imaginario han jugado un papel importante en la constitución de un corpus histórico-legendario, teñido a veces de una cierta fantasía”.

Precisamente, uno de los problemas previos que conlleva el estudio biográfico de Simón Bolívar es el carácter confuso y polémico que supone su iniciación masónica, negada por unos, afirmada por otros y desconocida o ignorada por los demás. Pero que en cualquier caso queda convertida en prueba o contraprueba de actuaciones políticas independentistas, no siempre suficientemente probadas con su vinculación o no masónica.

1 José Antonio Ferrer Benimeli, "Bolívar y la masonería”, Revista de Indias XLIII, no. 172 (julio-diciembre 1983): 631-632; Revista Estudos Ibero-americanos IX, no. 1 (julho-dezembro 1983): 1-51; "Masonería e independencia de Hispanoamérica: Miranda y las logias Lautaro", en La Masonería en la Independencia de América. Tres siglos de fundación de la masonería simbólica (1717-2017), eds. Diana Elvira Soto Arango, Miguel Angel Puig-Samper y José Pascual Mora-García (Tunja: Universidad Pedagógica y Tecnológica de Colombia, 2018), 15-45; "Las logias Lautaro, los Caballeros Racionales y el movimiento independentista americano", en Masonería y sociedades secretas en México, coords. José Luis Soberanes Fernández y Carlos Francisco Martínez Moreno (México: UNAM, 2018) 41-70; "Mito, olvido y manipulación de la historia de la masonería", REHMLAC+, 17, no. 1 (mayo-noviembre 2019) 1-11, https://doi.org/10.15517/rehmlac.v11i1.36976

2 Expresión que utiliza Fernando Marqués da Costa en su excelente prefacio a Alain de Keghel, La Francmasonería en América latina. Idealismo, complejidades y poder (Oviedo: Masonica.es, 2019), 15.

3 Simón Bolívar en realidad se llamaba Simón José Antonio de la Santísima Trinidad Bolívar y Palacios, siendo sus padres Juan Vicente Bolívar y Ponte y Concepción Palacios y Blanco.

4 A pesar de que Angel Guisado Cuellar, "Masonería británica en Cádiz durante la guerra peninsular", St. Bernard's Lodge of Research No. 1817 S.C. Gibraltar Masonic Papers 1 (2015): nota 14, diga que "lo único demostrado de forma indudable es que el líder argentino San Martín fue masón”, pues ninguno de los dos trabajos en que se apoya tienen ese valor probatorio. Vida española del general San Martín, coord. Antonio Lago Carballo (Madrid: Instituto Español Sanmartiniano, 1994). Keghel, La Franc-Masonería en América latina, 273. 
Las biografías de Bolívar, al igual que ocurre con tantos diccionarios y enciclopedias ${ }^{6}$, en gran parte son ajenas al hecho de si fue o no masón. En general, resultan más bien decepcionantes por sus carencias, vaguedades y reiteraciones en esta cuestión. Si tomamos como ejemplo tres biografías de carácter popular y gran difusión, observamos que en una de ellas se habla solo de "Sociedad Patriótica”; en otra de "la logia de Cádiz" vinculada a la Gran Reunión Americana, cuya sede se encontraba en Londres; y en una tercera en un capítulo titulado "las logias en acción”. Lo único que se dice es que el movimiento de Miranda y Bolívar, como más tarde el de San Martín, habían sido apoyados por sociedades secretas llamadas "logias" como la que llevaba el nombre de Lautaro y funcionaba en Cádiz durante la guerra de independencia de España contra Napoleón. Como contrapartida en el entorno de la masonería existe la tradición que vincula a Bolívar con la masonería y en especial con las sociedades patrióticas o logias Lautaro ${ }^{10}$.

\section{Dónde y cuándo fue iniciado Bolívar en la masonería}

El masón William R. Denslow, en su obra 10.000 masones famosos dice que Bolívar ingresó en la masonería en Cádiz y añade que recibió los grados del rito escocés en París, siendo elevado a la jefatura de Caballeros Templarios en Francia en 1807, y que durante su misión diplomática en Londres, en el año 1810, llevó una vida activa en ese país. Después, fundó la logia Protectora de las Virtudes no. 1 en Venezuela, y la Libertad no. 2 en Perú, de las que habría sido su venerable maestro ${ }^{11}$. Pero no baja a más detalles como, por ejemplo, la fecha de su ingreso en la masonería de Cádiz, el nombre de la logia, ni qué masonería era esta. Hoy día sabemos que la primera logia masónica se constituye en Cádiz en enero de $1807^{12}$ y para esas fechas Bolívar ya había regresado a América, por lo que difícilmente pudo ingresar en la masonería en Cádiz.

Por su parte, el doctor Buenaventura Briceño Belisario, que fue Soberano Gran Comendador del Supremo Consejo 33 del rito escocés antiguo y aceptado para Venezuela, en su libro Humanos

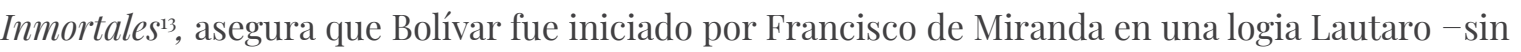
indicar cuál, dónde y cuándo- y recibió el grado de maestro en la logia venezolana de Carúpano

A su vez Carnicelli, al igual que Mancini a quien cita"15, aseguran que se inició en la "masonería mirandista” en la ciudad de Cádiz, en la logia Lautaro, sin tampoco indicar la fecha ni

$6 \quad$ A título de ejemplo basta acudir a la voz Simón Bolívar en alguna de las muchas enciclopedias o diccionarios que de él se ocupan para constatar que omiten cualquier referencia a su presunta pertenencia a la masonería. Esto ocurre, por ejemplo, con la Enciclopedia Universal Ilustrada europeo-americana (Barcelona: José Espasa e Hijos Ed. 1908), tomo VIII, 1408-1413; Diccionario enciclopédico Hispano-Americano de literatura, ciencias y artes (Barcelona: Montaner y Simón, 1888), tomo III, 744-745; Diccionario Enciclopédico Salvat (Barcelona: Salvat, 1955), 249-251; Gran Enciclopedia del Mundo (Bilbao: Durvan, 1962) tomo III, 725. Una excepción es la Nueva Enciclopedia Larousse (Barcelona: Planeta, 1980), 1262-1263, donde, bien informados, se dice que en Paris "se afilió a una logia masónica".

7 Demetrio Ramos Pérez, Simón Bolivar el Libertador (Madrid: Anaya, 2004), 47-49.

8 Nelson Martínez, Simón Bolívar (Madrid: $\mathrm{H}^{\mathrm{a}} 16$ Quorum, 1986), 15-16.

9 R. Ballester Escalas, Simón Bolivar (Barcelona: Toray, 1963), 145.

10 La elección del título "Lautaro" -el guerrero mapuche- es ya muy significativa, pues Lautaro, caudillo araucano, fue el que venció a Valdivia, el conquistador de Chile, en Tucapel en 1554.

William R. Denslow, 10.000 famous freemasons (Richmond: Macoy, 1957).

Ferrer Benimeli, Masonería española contemporánea (Madrid: Siglo XXI de España ed., 1980), 42-46.

Buenaventura Briceño Belisario, Humanos inmortales (La Habana: Lex, 1961).

Carúpano: ciudad de Venezuela situada en la costa del mar de las Antillas, en el estado de Sucre, a $65 \mathrm{kms}$. de Caracas.

Américo Carnicelli, La Masonería en la independencia de América (1810-1830) (Bogotá: El autor, 1970), tomo I, 207. Jules

Mancini, Bolivar y la emancipación de las colonias españolas desde los orígenes hasta 1815, citado por Carnicelli, La Masonería, tomo I, 207. 
dar más detalles. Y añaden que en Londres, en 1810, recibió del precursor Miranda el supremo grado iniciático en la Gran Logia Americana. Y como complemento de lo anterior traen el testimonio del historiador marqués de Villa Urrutia $^{16}$ en su estudio La reina María Luisa y Bolívar donde se afirma que Bolívar fue iniciado a fines de 1803 no en la logia Lautaro, sino en la Caballeros Racionales también de la ciudad de Cádiz ${ }^{17}$.

Michel Vaucaire's, en Bolívar el Libertador, relata que tras su viaje a Europa en 1803 - una vez fallecida su esposa María Teresa el 22 de enero de ese año- y ya de retorno a Venezuela, vía Estados Unidos, en 1806, le enseñó su diploma masónico y le refirió la visita a la logia de Cádiz "a la que acudió por curiosidad y no por convicción”".

Este testimonio, al igual que los anteriores no tienen valor para Seal-Coon en su riguroso trabajo Simón Bolívar, freemason ${ }^{19}$. Los primeros por ser contradictorios y no aportar ninguna prueba. Este último porque Bolívar a finales de 1803 tenía 20 años y era un oficial español, no un revolucionario, que venía a Madrid a mitigar el dolor de haber perdido a su esposa a los seis meses de casado ${ }^{20}$. Y para Seal-Coon ninguna de estas circunstancias era favorable para pensar en la posibilidad de la iniciación de Bolívar en una logia política. Lo más que admite es una visita como no masón.

Pero es más importante saber que la "logia” Lautaro o de Caballeros Racionales, de Cádiz, no existía todavía en 1803 ya que fue fundada en 1811 por Carlos de Alvear y no por Miranda, como se ha dicho. Además, la Lautaro no era una logia masónica, sino una sociedad secreta patriótica que tenía como fin la independencia de la América española ${ }^{21}$. La leyenda de la iniciación de Bolívar en Cádiz no tiene sentido, ya que en las fechas indicadas no había ninguna logia masónica en Cádiz, y la supuesta Lautaro tampoco existía y todavía tardaría siete u ocho años en ser constituida por Alvear, según su propio testimonio²2.

Tampoco hay pruebas de que Bolívar fuera miembro, ni mucho menos fundador, de la logia Protectora de las Virtudes que fue establecida en Barcelona (Venezuela) el $1^{0}$ de julio de 1810 por Diego Bautista Urbaneja; ni tampoco de la logia Orden y Libertad no. 2, de Lima (Perú). Fundación que se atribuye al general Antonio Valero con quien Bolívar tendría en 1826 palabras no excesivamente fraternales, a causa de las logias constituidas por dicho general Valero ${ }^{23}$. Los primeros contactos de Bolívar con la masonería fueron poco después, y no con la masonería

16 Wenceslao Ramírez de Villaurrutia (La Habana 1850-Madrid 1933), diplomático (embajador en Viena, Londres, Roma y París), historiador (miembro de la Real Academia de la Historia) y político (senador vitalicio en 1905 y ministro de Estado del 27 de enero al 23 de junio de 1905 en el gobierno presidido por Raimundo Fernández Villaverde) sin embargo no tiene ninguna autoridad como historiador de la masonería.

17 Wenceslao Ramírez de Villaurrutia, "La reina María Luisa y Bolívar", Boletín de la Real Academia de la Historia 90 (1927): 297-315.

18 Michel Vaucaire's, Bolivar the liberator, citado por F.W. Seal-Coon, “Simón Bolívar, freemason”, Ars Quatuor Coronatorum 90 (1977): 232.

19 Seal-Coon, Bolivar, freemason, 231-247.

20 Simón Bolívar quedó viudo a los 19 años de edad al fallecer en Caracas su esposa María Teresa "de una fiebre maligna" el 26 de enero de 1803.

21 Ferrer Benimeli, "Cádiz y las llamadas logias Lautaro o Caballeros Racionales”, en De la Ilustración al Romanticismo. Ideas y movimientos clandestinos (Cádiz: Universidad, 1988); "Las logias Lautaro, los Caballeros Racionales", 41-70.

22 Enrique de Gandía, "La política secreta de la Gran Logia de Londres", Boletín de la Academia Nacional de la Historia (Buenos Aires, 1976), 208. Nicolás Eugenio Navarro, Tópicos Bolivarianos. Glosas al "Diario de Bucaramanga" (Caracas, 1933), 3132. Emilio Ocampo, Alvear en la guerra con el Imperio del Brasil (Buenos Aires: Claridad, 2003). Carnicelli, La Masonería, tomo II, 64. 
templaria como apunta Denslow, ni con la logia americana de Carúpano como asegura Briceño Belisario, sino con la masonería escocesa parisina.

\section{Sociedades secretas}

En cualquier caso estamos ante unas instituciones como Lautaro, Caballeros Racionales, Reunión de Americanos, Conjuración de Patriotas, Unión Americana, Supremo Consejo de América, Gran Logia Americana, entre otras. Todos estos nombres reciben para significar lo mis$\mathrm{mo}^{24}$, instituciones o sociedades que en verdad no tenían nada de masonería, aunque a veces adoptaran el nombre de logias ${ }^{25}$.

Ni siguiera hay acuerdo en la denominación y ubicación de estas "sociedades". Para Martínez Zaldúa y Enrique de Gandía ${ }^{26}$ los Caballeros Racionales de Cádiz no eran una logia, sino los miembros integrantes de la Gran Reunión Americana fundada en Londres, por Francisco Miranda en 1797. Sin embargo, para Fernando Nadra ${ }^{27}$ la sociedad fundada por el venezolano Miranda en Londres se llamaba la Lautaro o de los Caballeros Racionales. A su vez, María Teresa Berruezo León dice que "Miranda fundó en Londres la logia los Caballeros Racionales o Gran Reunión Americana que después sería trasplantada a Cádiz como filial de la logia madre”28.

Nicolás E. Navarro en La masonería y la independencia se pregunta: “eran éstas verdaderas logias masónicas? Bien cabría dudarlo”, se responde ${ }^{29}$. El masón Pedro A. Barboza de la Torre, de Maracaibo, en su obra mecanografiada titulada Simón Bolívar y la francmasonería ${ }^{30}$ menciona estas pseudologías mirandistas que dice eran "volantes" o itinerantes, tal vez a imitación de las logias militares bonapartistas ${ }^{31}$.

El propio testimonio de San Martín nos hace dudar de si la, por algunos llamada, logia Reunión de Americanos de Cádiz, fuera una sociedad o logia, o más bien "una reunión de america-

24 Francisco Morales Padrón, Historia de América (Madrid: Espasa Calpe, 1962), 87, en lugar de Caballeros Racionales dice Caballeros Nacionales.

25 D. Duthu, "San Martín y la logia Lautaro", Revista Eclesiástica del Arzobispado de Buenos Aires V (1905): 900-902; Juan Canter, "La Sociedad Patriótica y la logia Lautaro", La Nación, Buenos Aires, 10 octubre 1934; "La logia Lautaro y la revolución de octubre de 1812", La Nación, Buenos Aires, 3 octubre 1934; "La logia Lautaro y la independencia de América según Antonio R. Zúñiga", Crítica Histórica (Buenos Aires, 1933): 1-14; "La logia Lautaro y Mendoza", Revista de la Junta Provincial de Estudios Históricos II (Santa Fe, 1936): 79-80; Raúl Ruiz y Ruiz, "La logia Lautaro y la independencia de América", Revista de la Junta Provincial de Estudios Históricos XIV (Santa Fe, 1946): 73-82 y Revista San Martín 13 (Buenos Aires, 1947): 117-126; Fabián Onsari, San Martín, la logia Lautaro y la franc-masonería (Avellaneda, 1951); F. Pacífico Otero, "La logia Lautaro. Su valor y significado histórico", La Nación, Buenos Aires, 12 junio 1910; Benjamín Oviedo Martínez, "La logia lautarina", Revista Chilena de Historia y Geografia LXII (1929): 105-126; Mariano F. Paz Soldán, "La logia Lautaro", en Historia del Perú independiente (Lima, 1868-1870): tomo I, 228-232; Rómulo Avendaño, "La sociedad Lautaro. Rectificaciones históricas", Revista de Buenos Aires 19 (1869): 439-445; Augusto Barcia, San Martín y la logia Lautaro (Buenos Aires, 1950); Jaime Eyzaguirre, La logia lautarina y otros estudios sobre la independencia (Santiago de Chile, Ed. Fco. de Aguirre, 1973); Guillermo Furlong. "La logia Lautaro", Criterio X (Buenos Aires), 1930): 721-722; Enrique de Gandía, La política secreta de la Gran Logia de Londres (Buenos Aires, 1977); José Pettenghi, "San Martín en Cádiz, camino de América”, en Vida española del general San Martín, coord. Antonio Lago Carballo (Madrid, Instituto Español Sanmartiniano, 1994): 186-193.

26 Ramón Martínez Zaldúa, La masonería en Hispanoamérica (México, 1965), 15; Enrique de Gandía, "Los orígenes probables de la logia Lautaro", Símbolo (Buenos Aires) 47 (agosto 1990): 15-18.

27 Fernando Nadra, San Martín hoy (Buenos Aires: Ed. Cartago, 1974) 26.

28 María Teresa Berruezo León, "Londres una pionera de la propaganda americana independentista en Europa, 1808-1830", Cádiz e Iberoamérica 7 (1984): 18-22.

29 Nicolás E. Navarro, La masonería y la independencia (Caracas: Ed. Sur-America, 1928), 15-16.

30 Pedro A. Barboza de la Torre, Simón Bolívar y la francmasonería (Maracaibo: s.c. 1977).

31 Sobre la masonería bonapartista en España: Ferrer Benimeli, Masonería española contemporánea (Madrid: siglo XXI de España Ed. 1980), 38-81. 
nos", con minúscula, como refiere el propio San Martín en una carta escrita al general Ramón Castilla dos años antes de su muerte desde su destierro voluntario de Boulogne-sur-Mer, en Francia, en la que dice:

Como usted yo serví en el ejército español, en la península, desde la edad de trece a treinta y cuatro años, hasta el grado de teniente coronel de caballería. Una reunión de americanos en Cádiz32, sabedores de los primeros movimientos, acaecidos en Caracas, Buenos Aires, etc., resolvimos regresar cada uno al país de nuestro nacimiento, a fin de prestarle nuestros servicios en la lucha, pues calculábamos se había de empeñar.

Este testimonio aportado por José Pettenghi concluye con el siguiente y lapidario comentario: “Todo lo que se añada no son más que suposiciones”33.

Por su parte, William Spence Robertson, el más prestigioso biógrafo de Miranda, considera como una hipótesis la fundación en Londres por Miranda de esa influyente sociedad de revolucionarios hispanoamericanos que se llamó la logia Lautaro, que luego desempeñaría en la América del sur una gran actividad que fomentó la revolución. Además, añade que del examen de sus papeles inéditos "nada revela que pueda probar, sea que perteneciera a la Orden Masónica, sea que fuese el fundador de la logia Lautaro”.

De esta misma opinión es el masón Seal-Coon, quien concluye su valioso trabajo "La mítica masonería de Francisco de Miranda" con estas palabras: "A mi juicio es mucho más probable que nuestro famoso y pintoresco sudamericano no haya sido nunca miembro de un organismo masónico regular o irregular"34.

Sin embargo, la opinión de que Miranda fue el fundador de un club revolucionario hispanoamericano es adoptada entre otros muchos que no pudieron conocer ni consultar el rico archivo personal de Miranda, por el masón e ilustre historiador Bartolomé Mitre. En su Historia de San Martín y de la emancipación sudamericana ${ }^{35}$ dice a propósito de las conocidas como "logias mirandistas" ${ }^{36}$ que las sociedades secretas compuestas de sudamericanos, con tenden-

$32 \quad$ El subrayado es mío.

33 Pettenghi, "San Martín en Cádiz, camino de América", 188. Manuel Jesús Segado-Uceda, "José Francisco de San Martín. De héroe a proscrito", Iberian 2 (2011) 30-39.

34 "Tampoco se han encontrado pruebas susceptibles de indicar que haya iniciado jamás a revolucionarios como San Martín y Bolívar en una asociación de 'carbonari' sudamericanos. En realidad, ni siquiera existen rastros indicadores de que Miranda se encontrara nunca con San Martín". William Spence Robertson, La vida de Miranda (Caracas: Academia Nacional de la Historia, 2006): 158. F.W. Seal-Coon, "La mítica masonería de Francisco de Miranda", en La Masonería española entre Europa y América, coord. Ferrer Benimeli (Zaragoza: Gobierno de Aragón, 1993), tomo I, 107-126.

35 Bartolomé Mitre, Emancipation of South America (Londres, 1893). Historia de San Martín y de la emancipación sudamericana (Buenos Aires: Eudeba, 1968).

36 Francisco de Miranda es considerado el creador de unas asociaciones secretas a las que se afiliaron los americanos dispersos por Europa (O’Higgins de Chile, Nariño de Nueva Granada, Montúfar y Rocaforte de Quito, Caro de Cuba, Alvear de Argentina...). Sin embargo, en sus papeles privados que el propio Miranda encuadernó en más de 60 volúmenes y que de 1812 a 1926 estuvieron custodiados en Inglaterra no hay la menor alusión a estas sociedades. Cuando Miranda fue hecho prisionero en Venezuela en 1812, su secretario particular Antonio Leleux embarcó los documentos en un navío inglés rumbo a Curaçao donde permanecieron durante dos años. Después fueron remitidos a Inglaterra bajo la custodia de lord Barthust cuya familia los custodió hasta que el diplomático venezolano e historiador Caracciolo Parra Pérez los compró y trasladó a Caracas. La Academia Nacional de Historia de Venezuela publicó los primeros 14 tomos entre 1929 y 1933. Otros diez lo fueron entre 1934 y 1950. Mantienen la clasificación que Miranda dió a sus papeles: Viajes (1750-1805), Revolución francesa (1792-1808) y Negociaciones (1790-1810). Wilfredo Padrón Iglesias. "La masonería, un punto sombrío en la trayectoria de Francisco de Miranda", Revista de Estudios Latinoamericanos 2, no. 61 (2015): 23-24. Gloria Henríquez-Uzcátegui. Los papeles de Francisco 
cias a la emancipación de la América del Sur sobre la base del dogma republicano, se asemejaban mucho por su organización y por sus propósitos a las ventas carbonarias calcadas sobre los ritos de la masonería de las que no tenían sino sus formas y sus símbolos”37.

Estas mismas ideas las encontramos también en su otra obra Historia de Belgrano y de la independencia argentina donde en el capítulo XXIV del tomo segundo, bajo el epígrafe de "Belgrano y San Martín" dice que estas sociedades secretas

revestían todas las formas de las logias masónicas; pero sólo tenían de tales los signos, las fórmulas, los grados y los juramentos. Su objeto era más elevado, y por su organización se asemejaban mucho a las ventas carbonarias. Compuestas en su mayor parte de jóvenes americanos fanatizados por las teorías de la revolución francesa, no iniciaban en sus misterios sino a aquellos que profesaban el dogma republicano, dispuestos a trabajar por la independencia de la América ${ }^{38}$.

En estos pasajes se aprecia con claridad cómo Bartolomé Mitre describe la asociación política secreta atribuida a Miranda. Asociación muy distinta de la masonería e incluso de la carbonería de las que tan solo había tomado una superficial apariencia de signos, fórmulas, grados y juramentos secretos. Era una asociación secreta sí, pero una sociedad secreta de carácter político, para un propósito perfectamente definido que nada tenía que ver con el que pretendía la masonería ${ }^{39}$.

Pero como este es un tema que no hace mucho aborde ya en Cartagena de Indias. Centrado precisamente en la persona de Miranda, me remito a lo allí dicho y publicado ${ }^{40}$ así como a lo que en su día publiqué sobre las logias Lautaro ${ }^{41}$, pues lo que ahora nos interesa es lo relacionado con Bolívar y su iniciación masónica.

\section{Bolívar masón. Su iniciación}

Al dejar de lado las características políticas y no masónicas de las logias Lautaro, Caballeros Racionales o como se les quiera llamar, y al prescindir incluso del hecho, no probado, de que Bolívar tuviera sus contactos con dichos caballeros racionales en Cádiz o en Londres, por curiosidad o por convencimiento. Lo cierto es que Bolívar, cosa que no se puede probar de Miranda ${ }^{42}$, sí perteneció a la masonería europea al menos durante su breve estancia en París

\footnotetext{
de Miranda (Caracas: Biblioteca de la Academia Nacional de la Historia, 1984), 135.

Iris M. Zavala, Masones, comuneros y carbonarios (Madrid: Siglo XXI de España Ed. 1971).

Citado por Nicolás E. Navarro, Masones, comuneros y carbonarios (Madrid: Siglo XXI de España Ed. 1971).

De la misma opinión era el profesor Salvador M. Dana Montaño (ex-rector de la universidad del Litoral y profesor de las universidades de Trelew y Santa Fe, en Argentina, en nuestra correspondencia particular (años 1975-1987) en torno a San Martín del que dice que "en ningún documento público ni privado, el general San Martín menciona a la masonería". Y añadía: "yo pienso que no fue masón, sino miembro de una sociedad secreta de tipo político, como la de Mazzini en Italia, o la de Echeverría en Buenos Aires".

40 Ferrer Benimeli, "Masonería e independencia de Hispanoamérica", 15-45.

41 Ferrer Benimeli, "Cádiz y las llamadas "logias" Lautaro", 149-176. Ferrer Benimeli, "Les Caballeros Racionales, les loges lotariennes et les formes deviées de la franc-maçonnerie dans le monde hispanique”, en Sous le masque de la Franc-Maçonnerie, ed. Jacques Lemaire (Bruxelles: Editions de L’Université, 1990), 11-30.

42 Seal-Coon, "Spanish-American revolutionary Masonry. The mythical masonry of Francisco de Miranda", Ars Quatuor Coronatorum 94 (1981): 83-106. Seal-Coon, "La mítica masonería de Francisco de Miranda", 107-126. Padrón Iglesias, "La masonería”, 13-20.
} 
allá por los años 1804-1806.

Al prescindir de las hipótesis de trabajo más o menos sugestivas, si nos atenemos a la documentación masónica conservada, Simón Bolívar fue iniciado en la masonería, aunque no consta dónde. Ya que el primer documento nos lo presenta en el acto de recepción del grado de compañero masón, es decir, del segundo grado. Este es un documento manuscrito del que se ocupan Carnicelli y Seal-Coon³, propiedad del historiador venezolano Ramón Díaz Sánchez, quien certificó su origen y propiedad antes de depositarlo en el Supremo Consejo del Grado 33 de la República de Venezuela.

\section{El documento en cuestión dice textualmente lo siguiente:}

A la Gloria del Gran Arquitecto del Universo. El día 11 del $11^{\circ}$ mes del año de la Gran Luz $5805^{44}$ los trabajos de Compañero han sido abiertos al Este por el R. $\mathrm{h}^{\mathrm{o}}$ de la Tour d'Auvergne, siendo iluminados el Oeste y Sur por los RR. hh. Thory y Potu. Hecha y sancionada la lectura de la última plancha trazada, el Venerable ha propuesto elevar al grado de Compañero al ho Bolívar recientemente ${ }^{45}$ iniciado, a causa de un próximo viaje que está en vísperas de emprender. Habiendo sido unánime la opinión de los hermanos para su admisión y el escrutinio favorable, el ho Bolívar ha sido introducido en el templo, y tras las formalidades de rigor ha prestado al pie del trono la obligación acostumbrada, situado entre los dos Vigilantes, y ha sido proclamado caballero Compañero masón de la R. Logia Madre Escocesa de San Alejandro de Escocia. Este trabajo ha sido coronado con una triple aclamación (hurra) ${ }^{46}$, y el $h^{\circ}$ habiendo dado las gracias ha tomado lugar a la cabeza de la Columna del Mediodía.

\section{Los trabajos han sido cerrados de la manera acostumbrada.}

A continuación, vienen ocho firmas, entre ellas la de Simón Bolívar. Se trata de una hoja del libro de actas de la logia San Alejandro de Escocia ${ }^{47}$, ubicada en París "en un subterráneo

43 Carnicelli, La Masonería, tomo I, 121; Sean-Coon, "Simón Bolívar freemason”, 231-248.

44 De hecho en la terminología masónica se suele usar más "el año de la Verdadera Luz" en lugar de la "Gran Luz".

45 En el original se utiliza la expresión nouvellement, que en español tiene dos traducciones diferentes: nuevamente y recientemente. Seal-Coon en su trabajo ya citado Simón Bolivar freemason (233) utiliza la expresión newly initiated y sugiere que tal vez hubiera sido iniciado en Cádiz. Pero aparte de que por el contexto la traducción correcta es la de recientemente -también utilizada por Carnicelli- hay otro error en Seal-Coon y es que la presunta logia Caballeros Racionales de Cádiz todavía no había sido fundada en Cádiz y además no puede entenderse como una logia masónica sino como una sociedad patriótica; y su pertenencia no implicaba ninguna iniciación propiamente masónica válida para la auténtica masonería.

46 En masonería la aclamación sigue a la batería. Batería es un rito que consiste en aplaudir un cierto número de veces, según el grado en el que este rito se practica. El venerable y vigilantes suelen participar de la batería golpeando con los respectivos malletes en sus mesas. La aclamación es pronunciada por los masones puestos de pie, la mano derecha elevada y el brazo extendido horizontalmente. En la masonería francesa existen dos aclamaciones tradicionales. La primera utiliza la fórmula vivat, vivat, semper vivat -que viva, que viva, que viva siempre-; la segunda, que todavía subsiste en el rito escocés, es el triple "houzzé" o "houzza". Esta última expresión es la usada en el documento en cuestión. El origen de esta palabra, "houzzé" o "houzza", todavía no está completamente clarificado, a pesar de los trabajos de Lantoine. Según Delaunay (Manuel maçonnique, Paris, 1821) y Vuillaume (Manuel Maçonnique, Paris, 1820), significaría "Viva el rey". Lantoine (Le Rite Ecossais Ancien et Accepté, Paris, 1930) ve simplemente una deformación de la vieja exclamación inglesa "hurrah". La batería de alegría se hacía siempre en honor de un suceso feliz para la logia o un hermano, y era natural en los masones escoceses el uso de esta aclamación. 47 Carnicelli, La masonería, tomo I, 123-127. La reproducción fotográfica en la página 129, y en Seal-Coon, Simón Bolivar, 233. La logia de Bolivar de París (http://www.diariomasonico.com/historia/bolivar-y-la-francmasoneria) a un desafortunado error al creer que dicha firma correspondía a una masona y que por lo tanto Bolívar recibió el $2^{\circ}$ y $3^{\circ}$ grado en la "prestigiosa logia mixta San Alejandro de Escocia". Sin embargo en el cuadro de dicha logia queda claro que Jeanne de la Salle es apellido, y su nombre Thomas, antiguo marino que ejercía en la logia el cargo de $2^{\circ}$ diácono. 
(sótano) del boulevard Poissonnière”, según Coen-Dumesnil y en la rue Coq-Heron, según Jacques Simon ${ }^{48}$. Allí se dice que el venerable propone elevar al grado de compañero al hermano Bolívar, recientemente iniciado, a causa de un viaje próximo que está en vísperas de emprender. Agrega que, después de las formalidades requeridas, Bolívar fue proclamado caballero compañero masón, colocándose a la cabeza de la columna del mediodía. Estamos ante un acta o documento masónico fechado el $11^{\circ}$ mes del año de la Gran Luz 5805, que equivale a enero de 1806 de la era vulgar, si tenemos en cuenta que el calendario masónico empieza en el mes de marzo ${ }^{49}$.

Además, disponemos de otro documento en doble versión (manuscrita e impresa) en el que Bolívar aparece ya como maestro, es decir, un grado superior. Sin embargo, este nuevo documento está fechado en 1804, un año antes. Se trata del "Cuadro General de Miembros que componen la Respetable Logia Escocesa de San Alejandro de Escocia, al Oriente de París” del año de la Gran Luz 5804, de la Restauración 5564 y de la Era Vulgar del año 13. En otras palabras el año 1804 y el 13 de la Revolución.

Una posible explicación de este desfase en la datación de ambos documentos tal vez se deba a que este último se refiera no solo a 1804, sino también a 1805, ya que no especifica ni el día ni el mes, los cuales están en blanco. Podría tratarse de un encabezamiento 'standard' en el que no se rellenaron los datos precisos, incluida la corrección del año, como a veces ocurre con los impresos de hoy día. También, puede tratarse del cuadro de 1804 al que se le añadieron nuevos datos de 1805, como también solía ocurrir. En cualquier caso, estamos ante otro documento auténtico, que ha sido conservado en la Biblioteca Nacional de París, en el fondo masónico del Gabinete de Manuscritos [F.M.². 100 bis, Dossier 3].

Allí aparecen seguidos dos nombres: Emmanuel Campos “noble español, maestro masón” y Simón Bolívar "oficial español, maestro masón”. A título de curiosidad hay que añadir que este es el único cuadro lógico en que aparece el nombre de Bolívar. En la columna correspondiente no figuran las firmas reglamentarias de ninguno de los dos, ni la de Campos, ni la de Bolívar. Esto quiere decir que o bien no asistieron a la tenida o reunión masónica de final de año (generalmente el 27 de diciembre, día de San Juan) para consignar sus firmas en el documento en cuestión; o bien que para esas fechas estaban ausentes de París. Al menos, por lo que

48 Antoine Coen - Michel Dumesnil de Gramont, La Franc-Maçonnerie Écossaise (París: E.E. Figuière, 1934) 25-26. Jacques Simon, Histoire du Rite Écossais Ancien et Accepté en France. Tome I: Des origines de la franc-maçonnerie à 1900 (París: Dervy, 2019), 90.

49 La fecha masónica utilizada, al no ser uniforme el calendario masónico, no es fácil precisar su correspondencia en nuestro calendario gregoriano. A este propósito Manuel Pérez Vila, “La experiencia masónica de Bolívar en París” en Visión diversa de Bolivar (Caracas: Ed. de Pequiven, 1984), 333-334, dice lo siguiente: "Si el acta perteneciese a una logia inglesa o norteamericana del rito ortodoxo (que no es el caso), no habría duda alguna: el $11^{\circ}$ día del mes $11^{\circ}$ del año 5805 sería el 11 de noviembre de 1805, pues allí el año masónico empieza al mismo tiempo que el civil, el 1 de enero, y al año se le agregan 4000 para remontarse a lo que entonces se consideraba la fecha de la creación del mundo. Pero si el acta hubiese sido hecha en una logia francesa dependiente del Gran Oriente de Francia, el $11^{\circ}$ día del $11^{\circ}$ mes de 5805 correspondería al 11 de enero de 1806, pues esas logias también le agregaban 4000 años al de la era cristiana, pero hacían empezar el año masónico en marzo y no en enero. Pero como el acta relativa a Bolívar corresponde a una logia escocesa del rito antiguo y aceptado, el asunto se vuelve más complicado, pues, además de agregar 4000 años y de empezar el cómputo en marzo, los escoceses no principian forzosamente su año el día 1 de marzo sino que siguen el calendario hebráico en el que los meses son lunares, y no son idénticos de un año para otro, siendo necesario establecer una tabla de equivalencias. Lo más que se puede decir es que el día en que Bolívar fue ascendido a compañero en la logia San Alejandro de Escocia, de Paris, debe situarse dentro de la primera quincena de enero de 1806”. Sobre Calendarios masónicos en La Masonería, Extra IV de Historia 16 (noviembre 1977): 134-136. 
respecta a Bolívar sabemos que la urgencia en recibir el grado de compañero fue por causa de un inminente viaje que tenía que hacer, y que de hecho hizo, bien se trate del año 1804 o del año 1805.

Efectivamente, Bolívar que tenía una gran admiración por Napoleón como símbolo de la libertad y de la gloria, experimentó una gran decepción a raíz de su autocoronación como emperador en la catedral de París el 2 de diciembre de $1804^{50}$. El hecho de que Napoleón ciñera la corona imperial rompió en Bolívar el mito que se había forjado en torno a su figura:

Yo le adoraba como el héroe de la República, como la brillante estrella de la gloria, el genio de la libertad. En el pasado yo no conocía nada que se le igualase, ni prometía el porvenir producir su semejante. Se hizo Emperador, y desde aquel día le miré como un tirano hipócrita, oprobio de la libertad y obstáculo al progreso de la civilización¹.

Esta decepción se agravó cuando unos meses después, el 15 de agosto de 1805, en Milán, volvía Napoleón a coronarse, esta vez como rey de los italianos. Eso hizo que Bolívar que se encontraba en Italia, evocando las glorias de la República Romana y tenía como testigo a su preceptor Simón Rodríguez, hiciera en el Monte Sacro de Roma su célebre juramento: "Juro por el Dios de mis padres, juro por ellos, juro por mi honor, y juro por mi patria que no daré descanso a mi brazo, ni reposo a mi alma hasta que haya roto las cadenas que nos oprimen por voluntad del poder español”־2.

Aunque todavía no se haya localizado el documento que lo atestigüe, lo más probable es que poco después de ser aceptado al grado de compañero, debió de recibir, y por el mismo motivo, el de maestro, pues con este grado -y no con el de compañero- figura en el citado cuadro de miembros de la logia San Alejandro de Escocia. Muy probablemente, y puesto que se habla de haber sido recientemente iniciado, Bolívar recibió los tres grados de aprendiz, compañero y maestro con poca diferencia de tiempo en la misma logia parisina. Pues en caso de haber sido iniciado en otra logia, la ceremonia de recepción del grado de compañero - relatada en el documento propiedad del historiador venezolano Ramón Díaz Sánchez- hubiera tenido que ir precedida del acto de afiliación a la logia en cuestión. Al no haber ninguna alusión a él lo correcto es pensar que recibió los tres grados en la logia parisina de San Alejandro de Escocia con muy poca diferencia de tiempo, posiblemente en los últimos meses o semanas de 1805. Pérez Vila matiza más al decir que, probablemente fue iniciado a comienzos de diciembre, o a fines del mes anterior ${ }^{53}$. Miriam Blanco-Fombona, una vez examinada la documentación que sobre la logia San Alejandro de Escocia se encuentra en la Biblioteca Nacional de París, cree que Bolívar fue iniciado como aprendiz el 27 de diciembre de $1805^{54}$.

\footnotetext{
$50 \quad$ Bolívar estaba en París cuando Napoleón se coronó emperador. Más aún el embajador de España invitó a Bolívar a formar parte de su séquito para presenciar la ceremonia en la catedral de Notre-Dame; pero no solo rehusó la invitación, sino que -según Villaurrutia- "se encerró todo el día en su casa". Ramírez de Villaurrutia, La reina, 314.

51 Ramírez de Villaurrutia, La reina, 313-314.

$52 \quad$ Nelson Martínez, Simón Bolivar, 18.

53 Pérez Vila, La experiencia, 334.

54 Miriam Blanco-Fombona de Hood, "La Masonería y nuestra Independencia”, El Repertorio Americano I (julio 1979): 59-70.
} 
Todavía existe en la Biblioteca Nacional de París un nuevo documento titulado "Cuadro de los hh. que componen la R. Madre Logia Escocesa de Francia, bajo el título distintivo de San Alejandro de Escocia al Oriente de París el año de la Gran Luz 5804 y 1805 ”, que viene a ser una repetición del anterior, pero ordenado por grados masónicos y en el que a continuación de los Caballeros Rosa Cruz ${ }^{55}$, se especifican los nombres de seis maestros, entre ellos Campos, gentilhombre español y Bolívar, oficial español ${ }^{56}$. A estos siguen un compañero, dos miembros de la Columna de Armonía, un miembro honorario y tres no residentes en todo el año.

Esta cuestión enlaza con otra dificultad menor o pequeña anomalía de los cuadros en cuestión. Y es que, según los Estatutos de la Orden Masónica en Francia ${ }^{57}$, publicados en 1806, se prohibía la recepción del grado de compañero antes de los veintitrés años, y del grado de maestro antes de los veinticinco. Por otra parte, la colación de los grados estaba supeditada a la asiduidad de las logias. Un aprendiz no podía ser recibido compañero si no había participado al menos en cinco sesiones; la maestría se concedía al compañero solo después de haber justificado su asistencia a siete asambleas. En síntesis, bastaba la presencia en las reuniones masónicas de un año para conseguir la posibilidad de acceder al grado supremo de la masonería azul, es decir, al de maestro. Sin embargo, los militares -y este era el caso de Bolívar- no solamente podían ser iniciados antes de los veintiún años, al igual que los hijos de masones ${ }^{58}$, sino que podían, excepcionalmente, ver cómo se les concedía más de un grado en un mismo día cuando su salida era inminente. Circunstancias ambas que se dieron en la persona de Simón Bolívar por ser militar y por tener que salir de viaje de forma inmediata. De hecho es sintomático que su nombre no figure ni en los cuadros de miembros de la logia de San Alejandro de Escocia anteriores a 1804 y 1805, ni tampoco en los posteriores ${ }^{59}$. Sin embargo, sí aparece el nombre de Emmanuel Campos en el cuadro de 1806, gentilhombre español de veinticuatro años, maestro masón, que vivía en la calle Richelieu. En este caso, sí está la firma de Manuel Campos ${ }^{60}$.

\section{Masonería francesa, no americana}

Y aquí hay que hacer todavía un par de reflexiones más. La primera que estamos en presencia, no de una sociedad patriótica americana al estilo de los Caballeros Racionales, sino de

\footnotetext{
$55 \quad$ Que son tres: un mariscal del Imperio y dos doctores en medicina, los tres oficiales del Gran Oriente de Francia.

56 En realidad subteniente del Regimiento de Milicias de Voluntarios Blancos de los Valles de Aragua. Fue en junio de 1810 -seis años después- cuando Bolívar sería promovido a coronel de milicias. Sin embargo en la filiación dada por él a la policía de París en abril de 1806 figura como "negociante domiciliado en España", aunque en la proporcionada a la logia lo hace como "oficial español".

$57 \quad$ Statuts de l'Ordre Maçonnique en France (París, 1806), cap. XII, sec. VII, 205.

58 Nótese aquí ya el influjo de Napoleón Bonaparte en la configuración de la que acabaría denominándose masonería bonapartista. Ferrer Benimeli, "A Maçonaria Bonapartista na Espanha”, en Formaçao Historica da Maçonaria (Rio de Janeiro: Academia Brasileira Maçonica de Letras, 1983), tomo I, 102-165.

59 Como recoge Demetrio Ramos en la biografía de Bolívar, este alarmado por los intentos de Miranda sobre Venezuela, decidió regresar a su patria. De París se dirigió a Hamburgo donde embarcó a finales de 1806 en un barco neutral llegando a Charleston el 1 de enero de 1807. Ramos, Simón Bolívar, 38.

60 De Manuel Campos, que se presenta como 'noble' o 'gentilhombre' español, es poco lo que se sabe. Posiblemente fuera iniciado por las mismas fechas que Bolívar, dado el orden de inscripción en el cuadro lógico. Unos años antes he localizado precisamente a un Manuel Campos, capitán de la Compañía provisional de Inválidos destacada en la Alhambra y que fue el que recibió como prisionero el 29 de agosto de 1794 al conde Aranda a raíz de su destitución como primer ministro y del proceso incoado por Carlos IV a instancias de Godoy. Pero no es posible se trate de la misma persona pues si Manuel Campos tenía 24 años en 1806, debería tener doce en 1794. Rafael Olaechea y Ferrer Benimeli, El Conde de Aranda. Mito y realidad de un político aragonés (Zaragoza: Ibercaja, 1998) 376.
} 
una masonería francesa que muy pronto acabaría, por un lado identificándose como una masonería bonapartista al servicio y uso de Napoleón; y por otro siendo el origen y principal órgano de la masonería escocesa de Francia. Masonería que no tiene nada que ver con las logias Lautaro mirandistas o sanmartinianas, que de masonería no tenían más que la utilización de la palabra logia, pues ni en sus estatutos o constituciones, ni en sus fines y reclutamiento tenían el más mínimo parecido con la masonería. Como muy bien lo atestigua, entre otras muchas cosas, el juramento que tenían que prestar los miembros de las "logias" lautarinas ${ }^{61}$.

Por otro lado, la masonería en la que ingresó Bolívar en París no tenía nada de "americana”. A pesar de lo escrito por Vicente González Loscertales, quien asegura que Bolívar se impregnó en París de las ideas ilustradas, de las nociones de independencia, soberanía popular, progreso y civilización, “que le llevaron a incorporarse a la masonería americana de París, donde alcanzó el grado de maestro" ${ }^{2}$.

Si analizamos la composición social de los 47 miembros que integraban la logia San Alejandro de Escocia el año en el que figura el nombre de Bolívar, encontramos el siguiente resultado: en primer lugar no hay más "americano" que Bolívar, quien, sin embargo, está inscrito como oficial español. Todos los demás son franceses a excepción de dos nobles venecianos y Manuel Campos, noble español. Entre las profesiones aparecen 10 militares, incluido Bolívar, 6 abogados y hombres de leyes, 6 médicos y doctores en medicina (entre ellos el regente de la Facultad de Medicina de París), 6 altos funcionarios, 5 propietarios, 2 empleados, negociantes y músicos, respectivamente, y uno de cada una de las siguientes profesiones: rentista, pintor, académico, marino, senador..., así como los tres nobles citados ${ }^{63}$. También, llama la atención que frente a la juventud de Bolívar que el 24 de julio de 1804 había cumplido veintiún años, figuran bastantes jubilados o antiguos militares, antiguos médicos, antiguos abogados, antiguos empleados, antiguos marinos, antiguos magistrados... Así, a la vista de los componentes de la logia y sus calidades, parece que queda excluida toda posible "conexión” americana. En la logia de Bolívar destacan, entre otros, dos miembros por sus obras y actividades posteriores, los dos grados 33: el conde Antoine Thory ${ }^{64}$ y Auguste de Grasse Tilly ${ }^{65}$.

Américo Carnicelli también aporta un nuevo documento titulado "Lista nominal de los

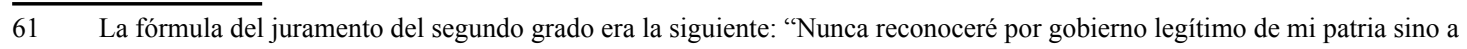
aquel que sea elegido por la libre y espontánea voluntad de los pueblos; y siendo el sistema republicano el más adaptable al gobierno de las Américas, propenderé por cuantos medios estén a mi alcance, a que los pueblos se decidan por él”. Mitre, Historia de Belgrano, vol. II, 213.

62 Vicente González Loscertales, "Bolívar: El hombre y el mito", Historia 1687 (julio 1983): 50.

63 No deja de ser curioso, pero así figuran en el Cuadro: de profesión, noble. Biblioteca Nacional de París. Gabinete de Manuscritos. Fondo F.M. ${ }^{2} 100$ bis. Dossier 3.

64 El historiador Antoine Thory es autor de Annales originis magni Galliarum O. ou Histoire de la fondation du Grand Orient de France et des révolutions qui l'ont précédée, accompagnée et suivie, jusqu'en mil sept cent quatre vingt dix neuf, époque de la réunion à ce corps de la Grande Loge de France, connue sous le nom de Grand Orient de Clermont ou de l'Arcade de la Pelleterie (París: Dufart, 1812) que posteriormente adoptó el título de Acta Latomorum ou Chronologie de l'Histoire de la Franche-maçonnerie française et étrangère (París: Dufart, 1815).

65 El conde Auguste de Grasse-Tilly, capitán de artillería, comisionado por el Supremo Consejo de Charleston, tras su estancia en las Antillas, desembarcó en Burdeos a comienzos de julio de 1804. Poco después está ya en París como propagandista y difusor del rito escocés antiguo y aceptado, fundador del Supremo Consejo del Grado 33 y miembro de la logia San Alejandro de Escocia. En 1806 lo encontramos en Italia, en 1809-1811 en España y en 1817 en Bélgica, según Carnicelli, Díaz y Pérez y Clavel. Carnicelli, La masonería, tomo I, 43; Nicolás Díaz y Pérez, La Franc-Masonería Española (Madrid: R. Fe, 1894), 211-213; F.T.B. Clavel, Histoire Pittoresque de la Franc-Maçonnerie et des Sociétés Secrètes anciennes et modernes (París: Pagnerre, 1843), 206 y 241. 
Mazones [sic] de altos grados que se saben en diversos cuerpos en el mes de abril de 1824", hecha por el Gran Comendador M. Ilt. Ho José Cerneau ${ }^{66}$. Son un total de 84 presuntos masones en posesión del grado 33. En dicha lista figura Simón Bolívar en el lugar cincuenta y ocho. Siguen otros listados con los grados 32 y 30 . Se trata de un documento sin ningún membrete o sello oficial, que perteneció al prócer José Félix Blanco, y que hoy se encuentra en Caracas en el Archivo General de la Nación ${ }^{67}$.

Personalmente, creo que el valor histórico de este documento es bastante escaso, por no decir nulo, aunque sí lo tenga desde el punto de vista testimonial. Presenta un parecido extraordinario con las numerosas listas que de presuntos masones existen entre los Papeles reservados de Fernando VII del Archivo del Palacio Real de Madrid, y que fueron confeccionados por la policía con base en presunciones, denuncias, sospechas, etc. Curiosamente, Seal-Coon en su ya citado y prestigioso trabajo titulado Simón Bolívar Freemason desecha este documento que ni siquiera menciona, a pesar de utilizar a Carnicelli como una de sus principales fuentes de información.

Nelson Martínez va más lejos en su Simón Bolívar al decir que desde que salió de Europa obró al margen de las decisiones de "una masonería cuya aparatosidad y misterio no parecen atraerle" ${ }^{68}$. De hecho Bolívar no figura ya en ninguna otra logia europea o americana. El propio Carnicelli que tanta documentación masónica utiliza, aunque no siempre señala las fuentes, es incapaz de decirnos una sola logia americana en la que Bolívar figure como miembro. Y cuando proporciona la Lista de masones de 1809 a $1828^{69}$ no puede menos de señalar a Simón Bolívar, Libertador, como miembro de la logia San Alejandro de Escocia de París, siendo el único que no aparece en logia americana. Lo que supone un reconocimiento indirecto de su no actividad masónica en la tierra que él liberó o independizó. Dicho con otras palabras, frente a uno o dos años de militancia masónica en París, estamos ante 25026 años posteriores de alejamiento masónico, o al menos de ausencia de noticias de una participación directa.

Testimonio que coincide con lo que el edecán de Simón Bolívar, Louis Perú de Lacroix escribe en su Diario de Bucaramanga. Allí dice que el Libertador le confesó: primero que se había hecho masón en París; luego que había abandonado la masonería porque no encontraba nada nuevo en ella, solamente repeticiones insustanciales" ${ }^{\circ}$.

66 De este mismo autor se conoce una obra titulada Senda de las luces masónicas (New York: Wingslang, 1821).

67 Archivo General de la Nación (Caracas). Papeles del prócer José Félix Blanco. tomo I, no. 298.

68 Nelson Martínez, Simón Bolivar, 16.

69 Carnicelli, La masonería, tomo II, 374-376.

70 Luis Perú de Lacroix, Diario de Bucaramanga (Caracas: Ed. de Nicolás E. Navarro, 1935), 77. Luis Perú de Lacroix, nacido en Francia el 14 de septiembre de 1780 en realidad se llamaba Luis Gabriel Juan de Lacroix Peroux, según Seal-Coon, y descendía de un linaje distinguido. Su biografía, según el mismo autor, se resume así: Sirvió de oficial en el ejército de Napoleón pero con la restauración de Luis XVIII tuvo que huir a las Antillas donde se unió al corsario francés Luis Aury en 1814. Este operaba bajo bandera mejicana y conquistó a los españoles la isla Old Providence. Establecido allí nombró a Lacroix comandante general, y Secretario de Estado de su "gobierno". Por este tiempo Lacroix adoptó una forma españolizada de sus nombres y apellidos. Aury murió en agosto de 1821 y entonces Perú de Lacroix ofreció sus servicios a la nueva república de Gran Colombia y fue enviado a Cartagena; luego encontró a Simón Bolívar con quien trabó amistad y fue condecorado por él en Bucaramanga donde escribió su famoso Diario de Bucaramanga. Elevado a general en 1830 fue llamado por Manuela Sanz, la querida de Bolívar en noviembre del mismo año, para que acudiera a San Pedro Alejandrino, Santa Marta, pues Bolívar quería verle. Llegó pocos días antes del fallecimiento de El Libertador. El otoño siguiente Perú de Lacroix fue exiliado por el gobierno anti-bolivariano y se marchó de Bogotá para Jamaica. En 1833 estaba en Caracas y en julio de 1835 se puso a la cabeza del movimiento rebelde reformista. Fue derrotado y Perú de Lacroix abandonó Venezuela y su familia, refugiándose en Francia. En París, a la edad de 56 años se suicidó. Seal Coon, "La isla de Jamaica y su influencia masónica en la Región”, en Masonería española y 


\section{Prohibición de las Sociedades Secretas}

A raíz del fracaso de la Convención de Ocaña en junio de 1828, que enfrentó a los partidarios del general Santander y los de Bolívar, y del también fracaso de la conspiración contra Bolívar y su intento de asesinato por la Sociedad Filológica, a finales de septiembre del mismo año ${ }^{71}$, Bolívar y sus ministros estimaron conveniente prevenir futuras conspiraciones, por lo cual, evitaron reuniones ilegales bajo el pretexto de sociedades culturales. Y al efecto expidieron el decreto de 8 de noviembre de 1828, donde prohíben en el territorio de la república de Colombia "las asociaciones o confraternidades secretas". Ciertamente, en el decreto no se menciona de manera concreta la masonería, pero tácitamente quedó incluida. Desde el 8 de noviembre de 1828 quedó disuelta de forma oficial la masonería en Colombia. Masonería que, introducida especialmente desde Jamaica, a partir de la década de 1820 adquirió un notable desarrollo, con mayor fuerza en el estamento militar.

De esta prohibición de Simón Bolívar, a quien junto con Francisco Miranda se suele situar en las filas de la masonería, siendo este precisamente uno de sus títulos de gloria o denigración (según el ángulo con que se mira) se suele hablar poco. No obstante, resulta curiosa la fundamentación ideológica que el mismo Bolívar hace en dicho decreto de la subsiguiente prohibición. Dice así:

\section{SIMÓN BOLÍVAR}

Libertador Presidente de la República de Colombia...

Habiendo acreditado la experiencia tanto en Colombia como en otras naciones, que las sociedades secretas sirven para preparar los trastornos políticos, turbando la tranquilidad pública, y el orden establecido; que ocultando tras ellas todas sus operaciones con el velo del misterio, haciendo presumir fundamentalmente que no son buenas ni útiles a la sociedad, y por lo mismo excitan sospechas y alarmas a todos aquellos que ignoran los objetos de que se ocupan, oído el dictamen del Consejo de Ministros,

\section{DECRETA:}

Artículo 1. ${ }^{\circ}$ Se prohiben en Colombia todas las asociaciones o confraternidades secretas, sea cual fuere la denominación de cada una.

Artículo 2. ${ }^{\circ}$ Los gobernadores de las provincias, por sí y por medio de los jefes de la Policía de los Cantones, disolverán e impedirán las reuniones de las sociedades secretas, averiguando cuidadosamente si existen algunas en sus respectivas provincias.

Artículo $3 .{ }^{\circ}$ Cualquiera que diera o arrendare su casa o local para una Sociedad Secreta incurrirá en la multa de 200 pesos, y cada uno de los que concurran, en la de 100 pesos por la primera vez y segunda vez; por la tercera y demás será doble la multa; los que no pudieren satisfacer la multa

América, coord. Ferrer Benimeli (Zaragoza: CEHME, 1993), tomo I, 219.

71 Sorprendieron la guardia que custodiaba la casa residencia del Libertador Presidente general Simón Bolívar, quien se salvó de ser asesinado por el valor de doña Manuela Sáenz quien le animó a lanzarse a la calle desde un balcón mientras ella entretenía a los conspiradores. Doña Manuela, llamada la Libertadora del Libertador fue su amante desde el 15 de junio de 1822, día en que se conocieron en Quito en el baile que don Juan Larrea dio en honor de Bolívar, quien acababa de llegar de Pasto. El idilio duró hasta la muerte del Libertador, ocurrida en San Pedro Alejandrino, Santa Marta, el 17 de diciembre de 1830. 
sufrirán por la primera y segunda vez dos meses de prisión; y por la tercera y demás, doble pena.

Parágrafo 1. ${ }^{\circ}$ Las multas se destinan para gastos de policía, bajo la dirección de los gobernadores de provincia.

El Ministro Secretario de Estado del Despacho del Interior queda encargado de la ejecución de este Decreto.

Dado en Bogotá a 8 de noviembre de 1828.

El Ministro Secretario de Estado del Despacho del Interior, fosé Manuel Restrepo.

Respecto a este decreto sobre las sociedades secretas hay quienes afirman que tal providencia estaba dirigida especialmente contra la masonería, como resultado de las divergencias suscitadas entre Bolívar y Santander. Sin embargo, más bien parece que con dicho decreto se pretendió acabar con ciertos grupos políticos que de otra forma más o menos velada conspiraban contra la estabilidad del gobierno. La masonería que contaba con partidarios, tanto de Bolívar como de Santander, no podía ser excluida a pesar de que Bolívar hubiese sido iniciado en ella veinticuatro años antes.

El decreto de Bolívar por el que se prohibían "todas las sociedades o confraternidades secretas sea cual fuere la denominación de cada una", trae a la memoria otro decreto, anterior en un año, fechado y publicado en Granada de España, el año de 1827. Lleva el siguiente título:

Edicto del Ilustrísimo señor Arzobispo de Granada en el que se comunica a todos los fieles de esta diócesis y se manda observar la Real Cédula de S.M. y señores del Consejo, por la que se manda guardar y cumplir la Bula, que en ella se inserta, de nuestro santísimo Padre León XII, en que se prohibe y condena de nuevo toda secta o sociedad clandestina, cualquiera que sea su denominación, con lo demás que se expresa ${ }^{72}$.

Decreto que coincide con la declaración casi textual al delimitar lo que se entiende por sociedades clandestinas. Al igual que Bolívar lo hace con las asociaciones o confraternidades secretas.

A raíz del decreto de 8 de noviembre de 1828 dado por el masón Simón Bolívar, se clausuraron todas las logias masónicas existentes en las diferentes ciudades de la República ${ }^{73}$. De esta forma, el Libertador de 1819 se convirtió en el Liberticida de 1828, según Antonio Caballero ${ }^{74}$.

72 Sobre los decretos similares que por esos años dio Fernando VII en España contra las sociedades secretas se ocupa Ferrer Benimeli, Masonería española, tomo I, 152-160.

73 Según Carnicelli, La masonería, tomo II, 307 fueron al menos una treintena de logias: La Unión, Fraternidad Colombiana y Concordia Colombiana, de Caracas; Concordia y Valor y Constancia, de Valencia; Unanimidad, Bolívar y La Guaira, de La Guaira; La Amistad y Libertad, de Puerto Cabello; Los Hermanos Regeneradores, de Maracaibo; Protectora de las Virtudes, de Barcelona; Perfecta Armonía, de Cumaná; La Virtud Premiada, de Carúpano; Amistad, de Barquisimeto; Unión Filantrópica, de Coro; Aurora, de San Felipe; San Juan de la Constancia, de Tocuyo; The Eastern Star of Colombia no. 379 y La Concordia no. 792, de Angostura; San Juan de la Margarita, de Isla Margarita; Fraternidad, Las Tres Virtudes Teologales y Beneficencia, de Cartagena; Fraternidad Bogotana y Los Corazones sensibles no. 20, de Bogotá; Concordia de Boyacá, de Tunja; Hospitalidad del Magdalena, de Honda; La Mejor Unión, de Panamá; y Ley Natural, de Guayaquil. Antonio Caballero, "La acción inútil”, Historia 16 VIII, no. 87 (julio 1983): 65-69. 


\section{Conclusión}

Creo que no es necesario recurrir a posibles estudios psicosomáticos o psicopatológicos de Bolívar ${ }^{75}$, y ni siquiera entrar en el juego de la dificultad dialéctica que entraña la constante contradicción bolivariana, para explicar que en un momento de su vida fuera masón. Quizá más por curiosidad que por otra razón, como asegura Madariaga, su detractor y al mismo tiempo admirador ${ }^{76}$. Y en otro llegara a considerar a la masonería como una ridiculez, según parece lo declaró a Perú de Lacroix en 1828 quien lo recoge en su Diario de Bucaramanga ${ }^{77}$, y que, poco después, la considerara no solo ridícula, sino perniciosa, prohibiéndola por decreto de 8 de noviembre de $1828^{7^{78}}$ y acabando prácticamente con su existencia en la Gran Colombia durante varios años.

Nos movemos entre el hombre y el mito, entre la leyenda y la historia. Mito y leyenda que no por eso empañan la historia ni al hombre, sino que los enriquecen enseñándonos a aceptarlos con sus paradojas y contradicciones, con su multiplicidad de matices, tal como son ${ }^{79}$. Sin más ropajes que los del interés que nos aproxima a la realidad y verdad de un hombre que en este caso tiene la doble aureola más que centenaria, y que a los doscientos treinta y siete años de su nacimiento se le sigue mirando, quizá excesivamente, mitificado y manipulado en su imagen en beneficio de supuestas ideologías bolivarianas muy alejadas de su realidad personal. Bolívar es un hombre del que, como se dijo en el Congreso Bolivariano de Caracas de 1983, hay que bajar de su pedestal y pasearlo por los barrios extremos de las ciudades y por tantas naciones hispanoamericanas para recordar su mensaje político o patriótico, masónico o simplemente humano, de confraternización, de integración, de independencia de coloniajes trasnochados (externos e internos), y de implantación definitiva de prácticas verdaderamente constituyentes y democráticas frente a tantos atropellos de derechos humanos, tantas inmoralidades administrativas y tantos gobiernos dictatoriales.

\footnotetext{
75 Diego Carbonell, Psicopatología de Bolivar (Caracas: Universidad Central de Venezuela, 1965).

Salvador de Madariaga, Simón Bolivar (Londres: Hollis-Carter, 1952), tomo I, 222.

Carlos Restrepo, "Informe sobre la Masonería y la Independencia", Boletín de Historia y Antigüedades 46 (Bogotá, 1959): 236. Codificación Nacional, tomo III, 437.

Y no como quisiéramos que hubiesen sido.
} 


\section{APÉNDICE I}

Notas biográficas de Bolívar antes de su iniciación masónica

Los Bolívar tienen su origen en Marquina, señorío de Vizcaya (España). De los primeros que hay noticias fidedignas son Simón Bolívar, el Viejo, que fue secretario de la Real Audiencia en Santo Domingo. En 1587 se encuentra ya en Caracas junto a su hijo Simón Bolívar el Mozo o el Americano, nacido en Santo Domingo. Fue el sacerdote fundador del Seminario Tridentino de Caracas. En 1593 recibió la encomienda de los indios quiriquires en la villa de San Mateo, germen de la hacienda familiar de los Bolívar.

A lo largo de los siglos XVII y XVIII los Bolívar ocuparon altos cargos en la administración colonial y en las milicias del rey de España. Fueron propietarios de minas, de extensas posesiones de tierras y de esclavos negros para el cultivo de sus plantaciones. La familia Bolívar alcanzó un gran prestigio social, formó parte de la llamada aristocracia mantuana. Contribuyeron a la construcción del puerto de La Guaira y a la defensa del territorio como oficiales de la Corona española.

En 1783, cuando Simón Bolívar tenía 3 años de edad falleció su padre el coronel Juan Vicente Bolívar y Ponte. Y en 1792, apenas cumplidos los 9 años vio morir también a su madre Concepción Palacios y Blanco. Ambos víctimas de la tuberculosis. La misma enfermedad que acabaría con Simón Bolívar en 1830 a los 47 años de edad. Simón y sus otros tres hermanos (Juan Vicente, Juana y María Antonia) quedaron al cuidado de su abuelo materno Feliciano Palacios. Simón, el más indisciplinado, tuvo como preceptor a Simón Rodríguez, autodidacta que marcó profundamente a su pupilo, y a Andrés Bello que le inculcó el interés por la historia y la geografía. A los 14 años empezó a recibir instrucción militar en el Regimiento de Voluntarios Blancos de los Valles de Aragua, donde un par de años después alcanzó el grado de subteniente.

\section{Primer viaje a España}

En enero de 1799, cuando Simón Bolívar tenía 16 años embarcó rumbo a España en el puerto de La Guaira. Al estar La Habana bajo asedio de los ingleses, su barco se vio obligado a hacer escala en Veracruz. De ahí se hizo a la mar y arribó en Santander el 30 de mayo, de donde se trasladó a Madrid. Allí le esperaba su tío Esteban Palacios en buenas relaciones de amistad con el Secretario de Estado Francisco de Saavedra, antiguo Intendente de Venezuela y amigo del padre de Simón Bolívar. Francisco de Saavedra, un año antes, en 1798 había sustituido a Godoy en la primera magistratura del Estado. El año 1800 el joven Bolívar participó de la vida social

y política de Madrid gracias al prestigio y amistades de su tío Esteban Palacios que también gozaba del favor de Francisco de Saavedra.

Pero en 1801 Godoy recuperó el poder, Saavedra fue desterrado y Esteban Palacios y su entorno encarcelados. Simón Bolívar fue acogido en la casa del caraqueño marqués de Ustáriz, antiguo ministro del Supremo Consejo de Guerra, ilustrado, liberal promotor de tertulias. Se 
ocupó de la formación de Bolívar, quien conoció a María Teresa, hija de otro criollo caraqueño, Bernardo Rodríguez del Toro, de la que se enamoró de tal manera que le pidió el matrimonio. Esto hizo que Rodríguez del Toro trasladara su hija a Bilbao a donde no tardó en llegar el propio Bolívar, perseguido por la policía de Godoy. De Bilbao se marcó Bolívar a Francia, donde en París fue testigo de los festejos por la paz de Amiens entre Napoleón e Inglaterra, y donde buscó cierta inmunidad o seguridad personal para poder volver a Madrid.

Así lo hizo poco después, y a los 19 años, el 25 de mayo de 1802 tuvo lugar en Madrid la boda de Simón con María Teresa. De Madrid marcharon los recién casados a La Coruña donde embarcaron con destino Caracas y la hacienda de San Mateo donde se asentaron. Pero a los cinco meses fallecía María Teresa de la fiebre amarilla, Bolívar quedó viudo a los 19 años.

\section{Segundo viaje a España}

A finales de octubre de 1803 iniciaba su segundo viaje a España. Esta vez desembarcó en Cádiz donde se encontraba su tío Esteban Palacios que había recobrado la libertad. Su estancia en Cádiz debió de ser breve pues en febrero de 1804 estaba ya en Madrid de donde partió con Fernando Rodríguez del Toro, primo de su esposa, hacia París. Allí se encontró, entre otros americanos, con Simón Rodríguez, su preceptor. Sabemos que Bolívar estableció su domicilio en la calle Vivienne, en el triángulo entre la Opera, la Bolsa y la Biblioteca Nacional. En París frecuentó las tertulias de Madame Fany, se encontró con Alexander von Humboldt y el naturalista Bonpland, con los americanos Montúfar, Rocafuerte, Tristan, entre otros. Y en París se inició en la masonería en la logia San Alejandro de Escocia... 


\section{APÉNDICE II}

Tableau Générale des Membres qui composent la Rble.. L. . Écossaise de St. Alexandre d'Écosse à l’Époque du ... Jour du ... Mois de la Gde.. L.• 5804, de la Resturation 5564 et de l'Ère Vulgaire le An 13

\begin{tabular}{|c|c|c|c|c|}
\hline $\begin{array}{l}\text { GODEFROID }^{+} \text {DE LA } \\
\text { TOUR D'AUVERGNE }\end{array}$ & $\begin{array}{l}\text { MAURICE MARIE } \\
\text { JOSEPH }\end{array}$ & $\begin{array}{l}\text { ANCIEN CAP }{ }^{\mathrm{TNE}} \cdot . \text { DU } \\
\text { REGT. DE BOUILLON }\end{array}$ & $\begin{array}{c}\mathrm{G}^{\mathrm{D}} \therefore \text { INSPECTEUR } \\
\text { DU } 33^{\circ}\end{array}$ & $\mathrm{V}^{\mathrm{BLE}} \therefore$ \\
\hline Thory & $\mathrm{C}^{\mathrm{de}}$. Antoine & $\begin{array}{c}\text { ancien avocat en Par- } \\
\text { lement }\end{array}$ & $\mathrm{G}^{\mathrm{d}} \cdot \therefore$ Inspecteur du $33^{\circ}$ & $1^{\text {er }} \cdot \therefore$ Surv $^{\mathrm{t}}$. \\
\hline Potu & Pierre François & Rentier & $\mathrm{G}^{\mathrm{d}}$. Eco. $\cdot$ & $2^{\mathrm{e}} \cdot$ Surv. $\cdot$ \\
\hline Burard & Guilleaume & Docteur en médecine & S. $\cdot P \cdot \cdot R \cdot \cdot S . \cdot$ & Ex-V $-V^{\text {ble }} \cdot$ \\
\hline de Pescheloche & Joseph-Louis Louvain & $\begin{array}{c}\text { Major du } 19^{\circ} \text { Régiment } \\
\text { de Dragons }\end{array}$ & $\mathrm{G}^{\mathrm{d}}$. Inspecteur du $33^{\circ}$ & $\begin{array}{l}\text { Vle } . . \text { d'honneur a } \\
\text { perpetuité fondateur }\end{array}$ \\
\hline Duron & Jean-Jacques Jerôme & $\begin{array}{l}\text { docteur régent de la } \\
\text { faculté de médecine de } \\
\text { París }\end{array}$ & “K. $\cdot \mathrm{S} . \cdot$ & ex-venerable \\
\hline Demouze (?) & & médecin oculiste & $\mathrm{G}^{\mathrm{d}} \cdot \therefore$ Ec. $\cdot$ & Ex-maître \\
\hline de Haupt & Fréderic Ch. Jn. & $\begin{array}{c}\text { membre de l'academie } \\
\text { Royale de Florence }\end{array}$ & $\mathrm{G}^{\mathrm{d}}$. Inspecteur du $33^{\circ}$ & Orateur \\
\hline Carion de Nisan & Henry & $\begin{array}{c}\text { Tribun } \mathrm{Ch}^{\text {as }} \text {. de a } \mathrm{G}^{\mathrm{d}} \text {. } \\
\text { Charte Ide La (?) }\end{array}$ & $\mathrm{R}+.$. Ec.. & Ad. a l'Orateur \\
\hline $\begin{array}{c}\text { Bernin de Champetre } \\
\text { (?) }\end{array}$ & & ancien employé & M. $\cdot P . \cdot$ & Secrétaire \\
\hline de Salase & François & ancien avocat & $\mathrm{G}^{\mathrm{d}} \cdot . \mathrm{E} \cdot \cdot$ & Sec $^{\mathrm{e}}$. adjoint \\
\hline $\begin{array}{c}\text { Bermond d'Alez } \\
\text { d'Anduze }\end{array}$ & Jean Joseph Augustin & ancien $\mathrm{C}^{\text {huc }}$.(?) et Vi-Gal & $\mathrm{S} \cdot \therefore \mathrm{G}^{\mathrm{d}} \cdot \cdot \mathrm{I} \cdot \cdot \mathrm{G}^{\mathrm{al}} . \mathrm{du} 33^{\circ}$ & Trésorier \\
\hline Dutillet de Villar & Joseph Henri & Propriétaire & $\begin{array}{c}\mathrm{R} . \cdot+. \mathrm{d} \mathrm{d}^{\prime} \mathrm{H} . \cdot \text { off. du } \\
\text { G.C. }\end{array}$ & 1. diacre \\
\hline Jeanne de la Salle & Thomas & ancien marin & Grand Ecossais & $2^{\mathrm{e}}$ diacre \\
\hline Pipelet de Montijeaux & & ancien avocat & $\mathrm{G}^{\mathrm{d}} \cdot$. Ec. $\cdot$ & Garde des Sceaux \\
\hline Burard & idem ut supra & & M. P. $\cdot$ & aumonier \\
\hline Boudier de la Moulière & & ancien $\mathrm{D}^{\text {cier }}$. Régent & & aumonier \\
\hline Le Clerc & & ancien Docteur Régent & M. $\cdot P . \cdot$ & architecte \\
\hline Martin de Mentque & & ancien Magistrat & $G^{\text {d. }}$ E. $\cdot$ & $\mathrm{M}^{\mathrm{e}}$. de Cerem. \\
\hline Borie & & $\begin{array}{c}\text { médecin de l'Hôtel } \\
\text { Dieu }\end{array}$ & Elu. & $\mathrm{M}^{\mathrm{e}}$. de Cerem. \\
\hline Valeure & Cirus & Senateur & $\begin{array}{c}\mathrm{G}^{\mathrm{d}} \cdot . \text { Cons }^{\text {teur }} \text { de l'Ordre } \\
33^{\mathrm{e}}\end{array}$ & $\mathrm{M}^{\mathrm{e}}$. de Cerem. \\
\hline d'Agrain Destribat & Charles Philippe & ancien Cap ${ }^{\text {ne }}$. & K.H. & $M^{\mathrm{e}}$. de Cerm. \\
\hline Thory de la Móthe & Hippolytte & au regt.. (?) & P. $\cdot$ D. $\cdot$ R. $\cdot$ S. $\cdot$ & Expért \\
\hline Bourdoi de la Mothe & & ancien avocat & $\mathrm{G}^{\mathrm{d}} \cdot \therefore \mathrm{E} \cdot \cdot$ & Ord. $\cdot$ des Ban ${ }^{\text {ets }}$. \\
\hline Lucipide(?) & & $\mathrm{G}^{\mathrm{d}}$. Chancelier & $\mathrm{G}^{\mathrm{d}} \cdot \therefore \mathrm{Ad}^{\mathrm{cer}} \cdot . \mathrm{du} 33^{\circ}$ & \\
\hline de Grasse Tilly & Auguste & Capne. de Cavale ${ }^{\mathrm{e}}$. & $\operatorname{Rep}^{t}$. du $\mathrm{G}^{\mathrm{d}} . \mathrm{M}^{\mathrm{e}} \cdot . \mathrm{du} 33^{\circ}$ & \\
\hline
\end{tabular}




\begin{tabular}{|c|c|c|c|c|}
\hline Marescalchi & Ferdinand & $\begin{array}{c}\text { M. des Vel: Esc }{ }^{\text {ses }} \text { de la } \\
\text { Rep. } \cdot \text { H: et Consul(?) } \\
\text { d'Etat }\end{array}$ & $\begin{array}{l}\text { Grand Of. et G. Conser- } \\
\text { vateur du G.O. }\end{array}$ & \\
\hline Rénier & Bernardin & Noble Vénitien & $\mathrm{G}^{\mathrm{d}} \because \mathrm{I} \cdot \because \mathrm{du} 33^{\circ}$. & \\
\hline Caleppio & Pierre & Noble Vénitien & $\mathrm{G}^{\mathrm{d}} \because \mathrm{I} \cdot \because \mathrm{du} 33^{\circ}$. & \\
\hline Serrurier & & $\mathrm{M}^{\text {al }} \therefore$ de l'empire & $\mathrm{R}+\mathrm{L} \cdot \therefore$ & \\
\hline Couppe & & an. $\cdot$ Groffier la Chef & $\mathrm{G}^{\mathrm{d}} \cdot \mathrm{du} 33^{\circ}$. & \\
\hline de July & & ancien officier & $\mathrm{M}^{\mathrm{e}} \cdot \therefore \mathrm{P} \cdot$. & \\
\hline de la Barte & & Propriétaire & Mè. .P. & \\
\hline Héroux & $\begin{array}{c}\text { Ange Louis Auguste } \\
\text { Pierre }\end{array}$ & Employé & Maître & \\
\hline Collinet & Louis-Pierre & Docteur en Médecin & $\begin{array}{c}\text { M. parfait et officier du } \\
\text { G. Orient }\end{array}$ & \\
\hline Dubreuil & & Docteur en Médecin & Off. $\because$ du G. $\because$ O. & \\
\hline Robelot & Hubert & homme de loi & M. & \\
\hline Campos & Emmanuel & Noble Espagnol & M. & \\
\hline Bolívar & Simón & Officier Espagnol & M. $\cdot$ & \\
\hline Perrin & & Propriétaire & M. $\cdot$ & \\
\hline Frasche & & Négociant & M. $\cdot$ & \\
\hline de $\mathrm{S}^{\text {te }} .$. Colombe & Pascual & Propriétaire & Comp. & \\
\hline Zancla & Paul & Négt. : & S. $\therefore$ P. $\cdot$ R. $\cdot++$ & \\
\hline Bianchi & Antoine & Comp. de Musique & $\mathrm{M}^{\mathrm{e}}$ & Int ${ }^{\text {de }}$ de l'harmonie \\
\hline Crus(s)aire & & peintre & ap.. & \\
\hline Pyron & & Propriétaire & $\mathrm{G}^{\mathrm{d}} . \mathrm{I} \cdot \therefore \mathrm{du} 33^{\circ}$ & M. $\cdot{ }^{\text {bre }}$ honnoraire \\
\hline Rieffler & & Musicien & M. $\cdot$ & Chef de la Musique \\
\hline Masse de Corneille & Nicolas Antoine & $\begin{array}{c}\text { avoué au } \mathrm{T}^{1} \text {. de ere } \\
\text { Instance }\end{array}$ & R.+ Ec. $\cdot$ & Membre \\
\hline
\end{tabular}




\section{APÉNDICE III}

\section{Situación de la masonería francesa cuando Bolívar ingresó en ella}

Las dos grandes ramas de la masonería universal, la inglesa y la escocesa tuvieron en Francia su propia historia. Las primeras logias creadas en Francia en el siglo XVIII lo fueron según el modelo y la influencia inglesa hasta que en 1758 la Gran Logia de Francia se proclamó independiente de la masonería londinense pero mantuvo la ortodoxia y los tres grados clásicos de aprendiz, compañero y maestro. Hasta 1773 no se creó el Grande Oriente de Francia.

Por su parte, los escoceses habían constituido la Grande y Soberana Logia de San Juan de Jerusalén, conocida también como la de los Emperadores de Oriente y Occidente ${ }^{80}$. El Consejo de esta Gran Logia envió a Etienne Morin para difundir el sistema escocés en los Estados Unidos y las Antillas donde predominaban las logias inglesas.

Los norteamericanos aceptaron el sistema escocés, llamado Rito de Perfección, que llegaba solo hasta el grado 25, pero lo aumentaron hasta el grado 33 y procedieron a la codificación del escocismo dando origen al rito escocés antiguo y aceptado. En 1801, en la ciudad de Charleston, en Carolina del Sur, fue creado el primer Supremo Consejo del grado $33^{8_{1}}$ en el que había un francés, con nacionalidad estadounidense, el capitán de artillería Alejandro Francisco Agusto, conde de Grasse-Tilly, que en 1804 fue comisionado por el Supremo Consejo como propagandista y difusor del rito escocés antiguo y aceptado. Tras una breve estancia en las Antillas, desembarcó en Burdeos a comienzos de julio de 1804. Poco después lo encontramos en París como fundador del Supremo Consejo del Grado $33^{82}$ y miembro de la logia San Alejandro de Escocia que se había mantenido fiel al escocismo frente al ya poderoso Gran Oriente. Al poco tiempo y gracias a las gestiones de Grasse-Tilly San Alejandro de Escocia se convertía en la Logia Madre Escocesa de Francia y Gran Logia General Escocesa del rito antiguo y acepta$\mathrm{do}^{83}$ con la intención de ser el centro de las diferentes logias de obediencia escocesa que hasta entonces habían permanecido en Francia sin relación entre ellas.

La constitución de esta Gran Logia General Escocesa tuvo lugar el 22 de octubre de 1804 en la sede la logia San Alejandro de Escocia. Acudieron, además de la logia anfitriona, San Alejandro de Escocia, las logias escocesas parisinas: La Parfaite Union, La Réunion des étrangers, Les Élèves de Minerve y Le Cercle oriental des Philadelphes. Ese mismo día Luis Bonaparte fue investido Gran Maestre de dicha Gran Logia General Escocesa, y un mes después, el 27 de noviembre, su hermano José Bonaparte se convertía en el Gran Maestro del Gran Oriente de Francia.

De esta forma se hizo patente y oficial la división de la masonería francesa que ya existía previamente. Frente al Gran Oriente de Francia se erigía el Supremo Consejo del Grado 33. Sin

80 Coen-Dumesnil, La Franc-Maçonnerie, 24.

81 Su jurisdicción se extendía al sur de los EE.UU. En 1813 fue creado otro Supremo Consejo en Washington con jurisdicción para los EE.UU. del norte.

82 Su sede estaba en "el local de la calle Neuve-des-Petits-Champs, conocida más tarde con el nombre de Galerie de Pompei. Clavel, Histoire Pittoresque, 241; Pérez Vila, La experiencia masónica, 329.

83 La constitución de esta Gran Logia General Escocesa fue notificada a todas las logias de Francia por una circular del 1 de noviembre de ese año. Pérez Vila, La experiencia masónica, 328. El 20 de octubre de 1804, de los diez miembros del Supremo Consejo seis pertenecían a la logia de Bolívar [la San Alejandro de Escocia]: Grasse Tilly, Thory, La Tour d'Auvergne, Bermond d'Alez d'Anduze, De Haupt y Bernardin Renier. Simon, Histoire du Rite Écossais, 88-89 
embargo, pocos días después, apenas tres semanas ${ }^{84}$ los responsables de ambos cuerpos, José Bonaparte en cuanto Gran Maestre del Gran Oriente de Francia y su hermano Luis Bonaparte, Gran Maestre de la Gran Logia General Escocesa, llegaron a un acuerdo. Según el cual el Gran Oriente de Francia ejercería su autoridad sobre los grados 1 al 18 y el Supremo Consejo del 19 al $33^{85}$. Pero este acuerdo resultó ser muy efímero pues el 6 de septiembre de 1805 los dignatarios del rito escocés rompieron con el Gran Oriente de Francia, y ambas instituciones volvieron a separarse $\mathrm{s}^{86}$.

Bolívar que fue testigo directo de estas desavenencias, y que ya tenía otras preocupaciones políticas más vitales y urgentes, no es extraño que se muestre decepcionado de su experiencia masónica parisina.

84 El tercer día del décimo mes del año 5804, según el calendario del sistema masónico escocés.

85 Según Clavel, Histoire Pittoresque, 242, el acuerdo se logró en la residencia del mariscal Kellerman. Albert Lantoine, $L a$ Franc-Maçonnerie écossais en France (París, 1925).

86 Clavel, Histoire Pittoresque explica con detalle esta crisis que se hizo ya patente en marzo de 1805. Jacques Simon, Histoire du Rite Écossais, 86-94. El 3 de diciembre de 1804 De Grasse Tilly fue destinado a Italia en calidad de adjunto al príncipe Eugène de Beauharnais y cesó como Soberano Gran Comendador del Supremo Consejo del Grado 33 en Francia siendo reemplazado por el príncipe archicanciller Cambacérès, nombrado el 8 de julio de 1806 e instalado el 13 de agosto. Poco después, el 4 de marzo de 1807, fue designado también gran maestre del rito escocés filosófico. 


\section{APÉNDICE IV}

Integrantes del Supremo Consejo de Francia el 20 de octubre de 1804.

* Alexandre François Auguste, conde Grasse, marqués de Tilly, Jefe de Escuadrón. Grado 33 desde el 21 de febrero de 1802.

Jean Nicolas Le Trichet, recaudador del registro del $8^{\circ}$ distrito de Paris. Grado 33 desde el 30 de septiembre de 1804 .

Jean-Baptiste Marie Paul Vidal, 24 años, propietario, natural de Marsella (Gran Secretario General). Grado 33, desde el 10 de octubre de 1804.

* Claude Antoine Thory, antiguo agente de cambio, banca y finanzas de la villa de Paris, propietario, 45 años. Grado 33 desde el 12 de octubre de 1804.

* Godefroid Maurice Marie Joseph La Tour d'Auvergne, antiguo capitán en el regimiento de Bouillon, infantería alemana. Grado 33 desde el 13 de octubre de 1804.

* Jean Joseph Henri Auguste Bermond d'Alez d'Anduze, antiguo canónigo, conde del antes capítulo noble y real de los condes de Vienne y vicario general de la diócesis de Bayeux. Grado 33 desde el 14 de octubre de 1804.

Jean-Baptiste Marie Adélaïde Timbrune de Valence, general de división, presidente del Colegio electoral del departamente del Marne. Grado 33 desde el 15 de octubre de 1805.

* Frédérick Charles Joseph de Haupt, capitán pensionado, antiguo Caballero de Malta

y de la Orden de Cristo, miembro de la academia real de Florencia. Grado 33 desde el 16 de octubre de 1804 .

* Bernardin Renier, ex-noble veneciano, miembro del antiguo consejo del Dogo. Grado 33 desde el 19 de octubre de 1804.

César Guillaume Robert de Trogroff, antiguo oficial de la administración de la marina, de 38 años de edad, natural de Guadalupe. Grado 33 desde el 20 de octubre de 1804.

[Los señalados con asterisco eran miembros de la logia de Bolívar] 


\section{Bibliografía}

Aguilar Meza, Ovidio. “En búsqueda de la verdad ¿Miranda fue masón?”. Biblioteca de autores y temas mirandinos. Los Teques: Ed. Simón Rodríguez, 2010.

Almeida de Carvalho, William. "Lojas Lautaro. Fatos e ficçoes". En La masonería hispano-lusa y americana. De los absolutismos a las democracias (1815-2015). Coordinado por José Miguel Delgado Idarreta e Yván Pozuelo Andrés. Oviedo: Universidad de Oviedo - CEHME, 2017.

Avendaño, Rómulo. “La sociedad Lautaro. Rectificaciones históricas”, La Revista de Buenos Aires 19 (1869): 439-445.

Ballester Escalas, R. Simón Bolívar. Barcelona: Ed. Toray, 1963.

Barboza de la Torre, Pedro A. Simón Bolívar y la francmasonería. Maracaibo: S.C., 1977.

Barcia, Pedro Luis. "San Martín y la Masonería”. En San Martín. Catolicismo y masonería. Buenos Aires: Instituto Nacional Sanmartiniano, 1993.

Barcia, Pedro Luis. San Martín y la logia Lautaro. Buenos Aires: Gran Oriente Federal Argentino, 1950.

Beltrán Avila, Marcos. La pequeña Gran Logia que independizó a Bolivia (1823-1825). Cochabamba: Ed. Atlantic, 1948.

Berruezo León, María Teresa. "La propaganda independentista de la logia mirandina en Londres”. En Masonería española y América. Coordinado por José Antonio Ferrer Benimeli. Zaragoza: CEHME, 1993.

Berruezo León, María Teresa. "Londres una pionera de la propaganda americana independentista en Europa, 1808-1830". Cádiz e Iberoamérica 7 (1984): 18-22.

Blanco-Fombona de Hood, Miriam. "La Masonería y nuestra Independencia”. El Repertorio Americano I (julio 1979): 59-70.

Boccia Romanach, Alfredo. La masonería y la independencia de América. Mitos e historia de las sociedades secretas. Asunción: Servi Libro, 2008.

Bohorquez, Carmen I. - Ghymers, Christian (coords). El papel de Miranda y su generación en la emancipación latinoamericana: identidad, integración regional y gobernabilidad. Caracas: ministerio del Poder Popular para la Cultura, 2006.

Bolívar, Simón. Discursos, proclamas y epistolario político. Selección Mario Hernández Sánchez-Barba. Madrid: Editora Nacional, 1978. 
REHMLAC+, ISSN 2215-6097, vol. 12, nos. 1-2, julio 2020 / diciembre 2020

Bolívar, Simón. Escritos políticos. Selección Graciela Soriano. Madrid: Alianza Editorial, 1981.

Bolívar, Simón. Páginas selectas. Selección de José Roberto Arce. Madrid: Aguilar Crisol, 1975.

Briceño Belisario, Buenaventura. Humanos inmortales. La Habana: Lex, 1951.

Brihuega, Nicolás. Masones en las Letras. Huellas masónicas en la literatura universal. Oviedo: masonica.es, 2019.

Caballero, Antonio. "La acción inútil”, Historia 16 VIII, no. 67 (julio 1983): 65-69.

Calvet Fagundes, Morivalde. "La masonería y la independencia de América Latina”. En Masonería española y América. Coordinado por José Antonio Ferrer Benimeli. Zaragoza: CEHME, 1993.

Canter, Juan. "La logia Lautaro y la independencia de América según Antonio R. Zúñiga”. Crítica Histórica I (1933): 78-90.

Canter, Juan. "La logia Lautaro y la revolución de octubre de 1812". La Nación, Buenos Aires, 3 octubre 1934 .

Canter, Juan. "La logia Lautaro y Mendoza". Revista de la funta Provincial de Estudios Históricos II (Santa Fe: 1936): 78-90.

Canter, Juan. “La logia Lautaro y su evolución”. La Nación, Buenos Aires, 10 octubre 1934.

Canter, Juan. "La Sociedad Patriótica y la logia Lautaro". La Nación, Buenos Aires, 10 octubre 1934.

Carbonell, Diego. Psicopatología de Bolívar. Caracas: Universidad Central de Venezuela, 1965.

Carnicelli, Américo. La masonería en la independencia de América (1810-1830). Bogotá: El Autor, 1970.

Carnicelli, Américo, Historia de la masonería colombiana (1833-1940). Bogotá: El Autor, 1975.

Carreras Damas, Germán. El culto a Bolívar. Caracas: Universidad Central de Venezuela, 1973.

Castro Olivas, Jorge Luis. Sociedades secretas y masonería en el proceso de emancipación peruana. Tesis de maestría en Historia, Universidad Nacional Mayor de San Marcos. Lima, 2009.

Catanzaro, Tomás. "Las Sociedades Patrióticas secretas de la emancipación”. Revista Luz 3, no. 9 (1952): 20 y SS.

Cerneau, José. Senda de las luces masónicas. New York: Wingslang, 1821.

Clavel, F.T.B. Histoire Pittoresque de la Franc-maçonnerie et des Sociétés secrètes anciennes et modernes. 
París: Pagnerre, 1843.

Coll y Prat, Narciso. Memoriales sobre la independencia de Venezuela. Madrid: Ed. Guadarrama, 1960.

Coen, Antoine - Dumesnil de Gramont, Michel. La Francmaçonnerie écossaise. Paris: E.E. Figuière, 1934.

Cuccorese, Ignacio Juan. San Martín y la masonería. Buenos Aires: Instituto Nacional Sanmartiniano, 1993.

Delaunay. Manuel maçonnique. Paris, 1821.

Denslow, William. 10.ooo famous freemasons. Richmond, Virginia: Macoy, 1957.

Díaz y Pérez, Nicolás. La Francmasonería española. Madrid: R. Fe, 1894.

Duthu, D. "San Martín y la logia Lautaro". Revista Eclesiástica del Arzobispado de Buenos Aires 5(1905): 900-902.

Eyzaguirre, Jaime. La logia lautarina y otros estudios sobre la independencia. Santiago de Chile: Ed. Francisco de Aguirre, 1973. Montevideo: América Una, 1988.

Fernández Cabrelli, Alfonso. La francmasonería en la independencia de Hispanoamérica. Montevideo: América Una, 1988.

Fernández Cabrelli, Alfonso. Masonería y sociedades secretas en las luchas emancipadoras de la Patria grande. Montevideo: America Una, 1975.

Fernández Cabrelli, Alfonso. Masonería, morenismo, artiguismo: prensa e influencia de la francmasonería en los movimientos independentistas del Río de la Plata. Montevideo: América Una, 1982.

Ferrer Benimeli, José Antonio. "Aproximación a la historiografía de la masonería latinoamericana". REHMLAC 4, No. 1 (mayo-noviembre 2012): 2-121. https://revistas.ucr.ac.cr/index.php/rehmlac/article/ view/12144

Ferrer Benimeli, José Antonio y Susana Cuartero Escobés. Bibliografía de la masonería, 3 vols. Madrid: Fundación Universitaria Española, 2014.

Ferrer Benimeli, José Antonio, "Masonería e Independencia de Hispanoamérica: Miranda y las logias Lautaro. En La Masonería y la Independencia de Hispanoamérica. Tres siglos de fundación de la masonería simbólica (1917-2017). Tunja: Universidad Pedagógica y Tecnológica de Colombia, 2018.

Ferrer Benimeli, José Antonio. “A Maçonaria Bonapartista na Espanha”. En Formação Historica da Maçonaria. Río de Janeiro: Academia Brasileira Maçonica de Letras 1983. 
Ferrer Benimeli, José Antonio. “Aproximación a las llamadas logias Lautaro”. Hoy es Historia IV, no. 23 (septiembre-octubre 1987): 45-58.

Ferrer Benimeli, José Antonio. “Bolívar masón?”. Historia 1696 (abril 1984): 109-118.

Ferrer Benimeli, José Antonio. "Bolívar y la Masonería”. Estudos Ibero-Americanos IV, no. 1-2 (julho-decembro 1983) 1-51.

Ferrer Benimeli, José Antonio. “Bolívar y la Masonería”. Revista de Indias XLIII, no. 72 (julio-diciembre 1983): 631-687.

Ferrer Benimeli, José Antonio. “Cádiz y las llamadas logias Lautaro o Caballeros Racionales”. En De la Ilustración al Romanticismo. Ideas y movimientos clandestinos. Cádiz: universidad, 1988.

Ferrer Benimeli, José Antonio. "La masonería y la independencia de América española (Reflexiones metodológicas)”. Anuario de Estudios Americanos 35 (1978): 159-177.

Ferrer Benimeli, José Antonio. "Las logias Lautaro, los Caballeros Racionales y el movimiento independentista americano”. En Masonería y sociedades secretas en México. Coordinado por José Luis Soberanes Fernández y Carlos Francisco Martínez Moreno. México: UNAM, 2018.

Ferrer Benimeli, José Antonio. "Les Caballeros Racionales, les loges lotariennes et les formes deviées de la franc-maçonnerie dans le monde hispanique”. En Sous le masque de la francmaçonnarie. Editado por Jacques Lemaire. Bruxelles: Ed. de l’Université, 1990.

Ferrer Benimeli, José Antonio. "Mito, olvido y manipulación de la historia de la masonería". REHMLAC+ 11, no. 1 (mayo-noviembre 2019): 1-11. https://doi.org/10.15517/rehmlac.v11i1.36976

Ferrer Benimeli, José Antonio. Masonería española contemporánea. Madrid: Siglo XXI de España Ed., 1980.

Fuentes Carvallo, Rafael. "Algunas consideraciones en relación a la fecha de llegada de Simón Bolívar por vez primera a España”. Boletín Histórico 39 (septiembre 1975): 393-398.

Furlong, Guillermo - Geoghegan, Abel Rodolfo. Bibliografía de la revolución de mayo (1810-1828). Buenos Aires: Biblioteca del Congreso de la Nación, 1960.

Furlong, Guillermo. “La logia Lautaro”. Criterio X (1930): 721-722.

Gandia, Enrique de. “Los orígenes probables de la logia Lautaro”. Símbolo 47 (agosto 1990): 15-18.

Gandia, Enrique de. "La política secreta de la Gran Logia de Londres". Boletín de la Academia Nacional de la Historia XLIX (1976): 207-242. 
González Bernaldo de Quirós, Pilar. “La Revolución francesa y la emergencia de nuevas prácticas de la política: la irrupción de la sociabilidad en el Río de la Plata revolucionario (1810-1815)”. En La Revolución francesa y Chile. Editado por Ricardo Krebs y Cristian Gazmuri. Santiago: Editorial Universitaria, 1990.

González Bernaldo de Quirós, Pilar. “Masonería y Nación: la construcción masónica de una memoria histórica nacional”. Historia 25 (1990): 81-101.

González Bernaldo de Quirós, Pilar. "Producción de una nueva legitimidad: ejército y sociedades patrióticas en Buenos Aires entre 1810-1813”. Cahiers des Amériques Latines 10 (1990): 177-195.

González Bernaldo de Quirós, Pilar. "Masonería y revolución de independencia en el Río de La Plata: 130 años de historiografía”. En Masonería, revolución y reacción. Coordinado por José Antonio Ferrer Benimeli. Alicante: Instituto Cultural Juan Gil-Albert, 1990.

González Bernaldo de Quirós, Pilar. Civilité et politique aux origines de la nation argentine. Les sociabilités à Buenos Aires (1829-1862). París: Publication de la Sorbonne, 1999.

González Loscertales, Vicente. “Simón Bolívar: el hombre y el mito”. Historia 1687 (julio 1983): 50-57.

Guedea, Virginia. "Las sociedades secretas de los Guadalupes y de Jalapa y la independencia de México”. En Masonería y sociedades secretas en México. Coordinado por José Luis Soberanes y Carlos Francisco Martínez Moreno. México: UNAM, 2018.

Guedea, Virginia. “Una nueva forma de organización política: la sociedad secreta de Jalapa 1812”. En Un hombre entre Europa y América. Homenaje a Fuan Antonio Ortega y Medina. Editado por Amaya Garriz. México: UNAM, 1993.

Guevara, Darío. Bolivar: libertador y arquitecto de la unidad americana. Quito, 1974.

Guillén, Julio. “Correo insurgente de Londres capturado por un corsario puertorriqueño, 1811”. Boletín de la Academia Chilena de la Historia XXVII, no. 63 (segundo semestre 1960): 125-155.

Guisado Cuellar, Angel. "Masonería británica en Cádiz durante la guerra peninsular". St. Bernard’s Lodge of Research no. 1817 S.C. Gibraltar Masonic Papers 1 (2015): 1-16.

Henríquez-Uzcátegui, Gloria. Los papeles de Francisco de Miranda. Caracas: Biblioteca de la Academia Nacional de la Historia, 1984.

Heredia, José Francisco. Memorias sobre las revoluciones de Venezuela. París: Garnier, 1895.

Herrera Valdés, Willy. Las sociedades secretas y la independencia política del cono sur americano: O’Higgins, San Martín y la logia Lautaro. Tesis de doctorado, Universidad Complutense de Madrid, 1985. 
REHMLAC+, ISSN 2215-6097, vol. 12, nos. 1-2, julio 2020 / diciembre 2020

Herrera, Michel, Iván, Bolívar y la francmasonería y La logia de Bolívar de París. http://www.diariomasonico.com/historia/bolivar-y-la-francmasoneria

Junco, Alfonso. "La masonería condenada por los prohombres de la independencia". Cuadernos Hispanoamericanos 30 (1952): 295-303.

Keghel, Alain de. La Francmasonería en América latina. Idealismo. Complejidades y poder. Oviedo: masonica.es, 2018.

Lahoud, Daniel. "La masonería en Venezuela y Nueva Granada (Colombia) en los primeros años del siglo XIX". Tierra Firme XXIV, no. 96 (2006): 621-632.

Lantoine, Albert. Histoire de la Francmaçonnerie française. París: Nourry, 1925.

Lantoine, Albert. La Francmaçonnerie écossais en France. París: 1925.

Lantoine, Albert. Le Rite Ecossais Ancien et Accepté. París: 1930.

Lappas, Alcibíades. La masonería argentina a través de sus hombres. Buenos Aires: Imprenta Belgrano, 1966.

Lappas, Alcibíades. San Martín y su ideario liberal. Buenos Aires: Símbolo, 1982.

Lappas, Alcibíades. "San Martín. El hombre de las logias”. Símbolo XXIV, nos. 71-72 (junio 1970) 186-192.

Lazcano, Martín V. Las sociedades secretas políticas y masónicas en Buenos Aires. Buenos Aires: El Ateneo, 1927.

Liévano Aguirre, Indalecio. Bolívar. Madrid: 1983.

López Albujar, Carlos. Masones y masonería en el Perú. Lima: Ed. José Pardo, 1961.

Madariaga, Salvador de. Simón Bolívar. México: Ed. Hermes, 1951 (Londres: Hollis Caster, 1952).

Maguirre, Patricio. La masonería y la emancipación del Río de la Plata. Buenos Aires: Nueva Hispanidad, 1961.

Mancini, Jules. Bolívar et l'émancipation des colonies espagnoles des origines à 1815. París: Perrin, 1912.

Manuel Maçonnique. París: 1820.

Martínez Zaldúa, Ramón. La Masonería Hispanoamericana. México: Ed. Costa-Amic, 1965.

Martínez, Nelson. Simón Bolívar. Madrid: Hª 16, 1987.

REHMLAC+, ISSN 2215-6097, vol. 12, nos. 1-2, julio 2020 / diciembre 2020 
Masur, Gerhard. Simón Bolívar. México: Grijalbo, 1980.

Mijares, Augusto. El Libertador. Caracas: 1964.

Mijares, Augusto. Simón Bolívar. Doctrina del Libertador. Selección de Manuel Pérez Vila. Caracas: Biblioteca Ayacucho, 1976.

Miranda, Francisco de. Archivo del General Miranda. 63 t. Caracas: Academia Nacional de la Historia, 1921-1939.

Mitre, Bartolomé. Emancipation of South America. Londres: Chapman, 1893.

Mitre, Bartolomé. Historia de Belgrano y la independencia argentina. 3 t. Buenos Aires: Ed. Félix Lajouane, 1887 .

Mitre, Bartolomé. Historia de San Martín y de la emancipación sudamericana. Buenos Aires: Eudeba, 1968.

Mora García, José Pascual. "Los comuneros, Francisco de Miranda y la francmasonería en Venezuela (1779-1810)”. Heurística 11 (enero-junio 2009): 74-92.

Morales Padrón, Francisco. Historia de América. Madrid: Espasa Calpe, 1962.

Nadra, Fernando. San Martín hoy. Buenos Aires, Ed. Cartago, 1974.

Navarro, Nicolás E. La masonería y la independencia. Caracas: Ed. Sur-America, 1928.

Navarro, Nicolás E. Tópicos bolivarianos. Glosas al 'Diario de Bucaramanga’. Caracas: 1933.

Ocampo, Emilio. Alvear en la guerra con el Imperio del Brasil. Buenos Aires: Claridad, 2003.

Olaechea, Rafael y José Antonio Ferrer Benimeli. El Conde de Aranda. Mito y realidad de un político aragonés. Zaragoza: Ibercaja, 1998.

Onsari, Fabián. San Martín, la logia Lautaro y la francmasonería. Avellaneda: S.E., 1951.

Orrego Vicuña, Eugenio. O'Higgins: Vida y tiempo. Buenos Aires: Losada, 1946.

Otero, F. Pacífico. "La logia Lautaro. Su valor y su significado histórico". La Nación, Buenos Aires, 12 junio 1910.

Oviedo Martínez, Benjamín. “La logia Lautarina”. Revista Chilena de Historia y Geografía LXLL (1929): $105-126$. 
REHMLAC+, ISSN 2215-6097, vol. 12, nos. 1-2, julio 2020 / diciembre 2020

Pacheco Quintero, Jorge. Influencia de la masonería en la emancipación de América (aspecto colombiano). Bogotá: Ed. Gran Colombia, 1943.

Padrón Iglesias, Wilfredo. "La masonería, un punto sombrío en la trayectoria de Francisco de Miranda". Revista de Estudios Latinoamericanos 2, no. 61 (2015): 13-30.

Parra-Pérez, Caracciolo. Páginas de historia y de polémica. Caracas: Litografía del Comercio, 1943.

Parra-Pérez, Caracciolo. Miranda et la Révolution française. Caracas: Ed. Banco del Caribe, 1989.

Paz Soldán, F. “La logia Lautaro”. En Historia del Perú independiente. Lima: 1868. I.

Pérez Tendero, Tomás. “Trayectoria Militar de Miranda”. Boletín Histórico 39 (septiembre 1975): $319-352$.

Pérez Vila, Manuel. "La experiencia masónica de Bolívar en París”. En Visión diversa de Bolívar. Caracas: Pequiven, 1984.

Perú de Lacroix, Luis. Diario de Bucaramanga. Caracas: d. Nicolás E. Navarro, 1935.

Pettengui, José. “San Martín en Cádiz, camino de América”. En Vida española del general San Martín. Coordinado por Antonio Lago Carballo. Madrid: Instituto Español Sanmartiniano, 1994.

Picirelli, Ricardo. San Martín y la logia Lautaro. Buenos Aires: Ministerio Educación y Justicia, 1958.

Picirelli, Ricardo. San Martín y la política de los pueblos. Buenos Aires: Aguirre, 1957.

Picón Salas, Mariano. Miranda. Mérida: Colección Clásicos merideños, 2006.

Pinto Lagarride, Fernando. La masonería y su influencia en Chile. Santiago: Orbe, 1978.

Pinto, Manuel. “Quién entregó al precursor?”. Boletín Histórico 39 (septiembre 1975): 277-318.

Ramírez de Villaurrutia, Wenceslao. "La reina María Luisa y Bolívar". Boletín de la Real Academia de la Historia 90 (1927): 297-315.

Ramos Pérez, Demetrio. Simón Bolívar el Libertador. Madrid: Anaya, 2004.

Restrepo, Carlos. "Informe sobre la masonería y la independencia". Boletín de Historia y Antigïedades 46 (1949): 232-237.

Reverón, Eloy. La masonería, Miranda, fuentes para su estudio. 21 de agosto de 2014. htpps://masoneriamirandina.blogspot.com/2014/ 
REHMLAC+, ISSN 2215-6097, vol. 12, nos. 1-2, julio 2020 / diciembre 2020

Reverón García, Eloy. "Mito y realidad en la historiografía masónica (1808-1830)". Anuario de Estudios Bolivarianos 4 (1915): 261-335.

Reverón García, Eloy. "El fantasma de Bolívar en la masonería venezolana”. Anuario de Estudios Bolivarianos 6 (1997): 243-345.

Reverón García, Eloy. El fantasma de Bolívar en la masonería venezolana. Caracas: Publicaciones Monfort, 2001.

Rodríguez Alonso, Josefina. Le siècle des Lumières conté par Francisco de Miranda. París: France-empire, 1974 .

Rojas, marqués de. El general Miranda. París, 1884.

Romero Juvenal. La Revolución de Mayo y la masonería. Buenos Aires: Hellas, 1960.

Romero, Celestino B. Raíz histórica de la masonería en Venezuela. Caracas, 1957.

Rottjer, Aníbal. La Masonería en la Argentina y en el mundo. Buenos Aires: Nuevo Orden, 1973.

Ruiz y Ruiz, Raúl. "La logia Lautaro y la independencia de América". Revista de la funta Provincial de Estudios Históricos XIV (Santa Fe, 1946): 73-82. Revista San Martín del Instituto Nacional Sanmartiniano 13 (1947): 117-126.

Rumazo González, Alfonso. Bolívar. Madrid: Edime, 1980.

Salcedo Bastardo, J. Visión y revisión de Bolívar. Buenos Aires: Imor. Logos, 1957.

Seal-Coon, F.W. “More Light: Simón Bolívar freemason”. Ars Quatuor Coronatorum 92 (1979): 231-248.

Seal-Coon, F.W. “Simón Bolívar, freemason”. Ars Quatuor Coronatorum 90 (1977): 231-248.

Seal-Coon, F.W. "Spanish-American revolutionari Masonry. The mythical Masonry of Francisco de Miranda”. Ars Quatuor Coronatorum 94 (1981): 83-106.

Seal-Coon, F.W. An Historical Account of Famaica Freemasonry. Kingston, 1976.

Seal-Coon, F.W. "La mítica masonería de Francisco de Miranda". En La masonería española entre Europa y América. Coordinado por José Antonio Ferrer Benimeli. Zaragoza: Diputación General de Aragón, 1993.

Segado-Uceda, Manuel Jesús. "José Francisco de San Martín. De héroe a proscrito”. Iberian 2 (2011): 30-39. 
Sheriff, Keith. The Rough Aslar. The History of English Freemasonry in Gibraltar: 1727-2002. Gibraltar: Grand Lodge of Gibraltar, 2002.

Simon, Jacques. Histoire du Rite Écossais Ancien et Accepté en France. París: Dervy, 2019.

Solar, Felipe Santiago del. La logia Lautaro y la independencia de Sudamérica. Santiago de Chile: Universidad La República, 2005.

Solar, Felipe Santiago del. "La francmasonería y la Independencia de América: un balance historiográfico”. En Primeras fornadas de Estudios Históricos de la franc-masonería chilena. Santiago de Chile: 2006.

Spence Robertson, William. La vida de Miranda. Caracas: Academia Nacional de la Historia, 2006.

Spence Robertson, William. Life of Miranda. North Carolina: The University of North Carolina Press, 1929.

Statuts de l'Ordre Maçonnique en France. París, 1806.

Thory, Antoine. Acta Latomorum ou Chronologie de l'Histoire de la Franche-maçonnerie française et étrangère. París: Dufart, 1815.

Thory, Antoine. Annales originis magni Galliarum O. ou Histoire de la fondation du Grand Orient de France et des révolutions qui l'ont précédée, accompagnée et suivie, jusqu'en mil sept cent quatre vingt dix neuf, époque de la réunion à ce corps de la Grande Loge de France, connus sous le nom de Grand Orient de Clermont ou de l'Arcade de la Pelleterie. París: Dufart, 1812.

Townsed, Andrés. Bolívar, alfarero de repúblicas. Buenos Aires, 1973.

Vaquero Iglesias, Julio Antonio. "Masonería e independencia americana según la historiografía decimonónica española”. En Masonería española y América. Coordinado por José Antonio Ferrer Benimeli. Zaragoza: CEHME, 1993.

Vaucaire's, Michel. Bolivar the liberator. Boston: 1929.

Vázquez Semadeni, María Eugenia. "La masonería en México entre las sociedades secretas y patrióticas". REHMLAC 2, no. 2 (diciembre 2010-mayo2011): 20-33. https://revistas.ucr.ac.cr/index.php/ rehmlac/article/view/6594

Vázquez Semadeni, María Eugenia y Kyle Jackson. "El triángulo masónico en el golfo de México y el Caribe, 1815-1820". En Gibraltar, Cádiz, América y la masonería. Constitucionalismo y libertad de prensa, 1812-2012. Coordinado por José Miguel Delgado Idarreta y Antonio Morales Benítez. Zaragoza: Gobierno de Gibraltar - CEHME, 2014. 
Vera, María Cristina. "Acerca de las relaciones entre la masonería y la política en América en tiempos de los revolucionarios liberales". Revista de la Funta Provincial de Historia 28 (2015): 215-251.

Vera, María Cristina. La vida de Miranda. Caracas: Academia Nacional de Historia, 2006.

Vicuña Mackenna, Benjamín. La revolución de la independencia del Perú. Santiago de Chile: Universidad, 1938.

Vicuña Mackenna, Benjamín. El ostracismo del General D. Bernardo O’Higgins. Escrito sobre documentos inéditos y noticias auténticas. Valparaíso: Librería del Mercurio, 1860.

Vicuña Mackenna, Benjamín. Vida del capitán general de Chile don Bernardo O’Higgins. Santiago de Chile: Rafael Jover, 1882.

Villanueva, Carlos A. La monarquía en América: Bolívar y el general San Martín. París: Librería Paul Ollenforft, 1911.

Villanueva, Carlos A. La revolución de independencia del Perú. Santiago de Chile: Universidad, 1938.

Zavala, Iris M. Masones, comuneros y carbonarios. Madrid: Siglo XXI de España ed., 1971.

Zeldis, León. "Freemasonry's Constitution to South American Independence. A factual Approach". Ars Quatuor Coronatorum 111 (1918): 78-101.

Zuñiga, Antonio R. La logia Lautaro y la independencia de América. Buenos Aires: J. Estrach, 1922. 